This item was submitted to Loughborough's Research Repository by the author.

Items in Figshare are protected by copyright, with all rights reserved, unless otherwise indicated.

\title{
Measuring and decomposing productivity change in the presence of mergers
}

PLEASE CITE THE PUBLISHED VERSION

https://doi.org/10.1016/j.ejor.2019.08.048

PUBLISHER

Elsevier

VERSION

AM (Accepted Manuscript)

PUBLISHER STATEMENT

This paper was accepted for publication in the journal European Journal of Operational Research and the definitive published version is available at https://doi.org/10.1016/j.ejor.2019.08.048.

\section{LICENCE}

CC BY-NC-ND 4.0

\section{REPOSITORY RECORD}

Arocena, Pablo, David Saal, Takuya Urakami, and Michael Zschille. 2019. "Measuring and Decomposing Productivity Change in the Presence of Mergers". figshare. https://hdl.handle.net/2134/10011839.v1. 


\title{
Measuring and Decomposing Productivity Change in the Presence of Mergers
}

\author{
Pablo Arocena ${ }^{a}$ \\ Universidad Pública de Navarra, Spain \\ David S. Saal ${ }^{\text {b }}$ \\ Centre for Productivity and Performance, Loughborough University, UK \\ Takuya Urakami ${ }^{\mathrm{c}}$ \\ Kindai University, Japan \\ Michael Zschille ${ }^{d}$ \\ Zentralinstitut für die kassenärztliche Versorgung, Germany
}

\begin{abstract}
${ }^{a}$ INARBE- Institute for Advanced Research in Business \& Economics. Universidad Pública de Navarra. Campus de Arrosadia. 31006 Pamplona, Spain. E-mail address: pablo@unavarra.es

${ }^{\mathrm{b}}$ Centre for Productivity and Performance, School of Business and Economics, Loughborough University, Loughborough, LE11 3TU, UK. E-mail address: D.S.Saal@lboro.ac.uk

${ }^{\mathrm{c}}$ Faculty of Business Administration, Kindai University. 3-4-1 Kowakae, Higashiosaka, 577-8502 Japan E-mail address: urakami@bus.kindai.ac.jp

${ }^{\mathrm{d}}$ Zentralinstitut für die kassenärztliche Versorgung in der Bundesrepublik Deutschland. Salzufer 8, 10587 Berlin, Germany. E-mail address: mzschille@,zi.de
\end{abstract}

\begin{abstract}
Managers and policymakers often encourage mergers and acquisitions of companies with the aim of increasing the productivity of the involved firms. However, problems with the measurement of productivity change usually occur when analyzing companies that merged during the period under consideration: while only individual predecessor firms exist in the base period, in the following period only the integrated company is observable. We therefore propose a new adaptation of the Malmquist index that is appropriate in the presence of mergers, which also allows for a detailed analysis of their effects on productivity change. Moreover, we believe that our methodological approach provides a useful widely applicable tool to identify the contribution of past mergers to productivity growth. We illustrate our merger consistent productivity decomposition, by using a sample of Japanese water supply systems observed in 2003, and the resulting consolidated and non-consolidated systems observed in 2009. On average, we find that mergers contributed positively to productivity change and that our merger consistent decomposition contributes to a better understanding of the determinants of productivity performance in the Japanese water sector.
\end{abstract}

Keywords: Productivity and competitiveness, Mergers and Consolidation, Malmquist Index, Japanese Water Supply. 


\section{Introduction}

Managers and policymakers around the world encourage mergers with the aim of increasing the productivity of the involved firms. Such potential productivity gains may stem from a number of direct and indirect effects. ${ }^{1}$ The direct effects come from the potential expansion of the production possibilities of the merged firm relative to that of their stand-alone predecessors. This category typically includes gains from (i) better integration or rationalization of production facilities e.g. production reorganization among the plants that belong to the merged firm so that relatively efficient plants that were underutilized before the merger turn out larger volumes; (ii) the management of production and demand, e.g. the adjustment of production to local demand with the effect than transport costs are reduced; (iii) better exploitation of size economies (e.g. if predecessor firms were operating under increasing returns to scale), and (iv) synergies by pooling certain functions and activities as well as scope economies from sharing common inputs. The indirect effects are related to the expectation that a merger challenges managers' behavior giving them incentives for making better management decisions. Thus, it is often argued that a merger: (i) improves cost discipline and thereby reduces slack and waste; (ii) enables the development of larger innovative abilities, and thereby leading to future productivity gains due to technological progress; and (iii) leads managers to make better decisions regarding firm scale and growth.

On the other hand, mergers often involve substantial business reconfigurations and organizational changes. It requires the integration of different, and often conflicting, corporate cultures, organization and management styles from the predecessors. Likewise, the presence of divergent political objectives and strategic priorities among the stakeholders of the predecessor firms usually plays a further disrupting role. Such differences may cause confrontation and resistance to implementing the changes that were assumed would be made by the merged firm (e.g. Bernad et al 2010), thereby negatively affecting the achievement of the benefits listed above, and even potentially resulting in poorer performance of the merged firm in comparison to the predecessor firms. The difficulties of actually integrating the predecessor firms following a merger have been widely addressed in the mergers literature (e.g. Teerikangas and Very, 2006; Capron et al, 1998). Further, it is also broadly consistent with the empirical evidence found in previous studies on the effects of mergers, in which the effects are very often found to be insignificant or even negative (e.g. Caves 1989). By contrast, some authors argue that the inconclusive results found in some empirical studies may be due to the fact that the periods of time in which the effects of mergers are assessed are too short, while the positive effects resulting from a merger are likely to be realized in the long run (e.g. Bernad et al 2010).

Assessing the realized impact of a merger is therefore a challenging task. Thus, problems with productivity analysis usually occur when analyzing companies that merged during the period under consideration. While only individual predecessor firms exist in the base period, in the following period

\footnotetext{
${ }^{1}$ Röller et al. (2001) provide an excellent summary of the potential efficiency gains from mergers.
} 
only the integrated company is observable (see e.g. Grifell-Tatjé and Lovell, 1996). A further challenge is to disentangle the observed productivity change into the different sources referred to above. Since the determinants of productivity growth are of interest however, the proportion of observed productivity change that can be properly attributed to the merger needs to be distinguished from other effects such as technical efficiency change, technical change, and subsequent post-merger scale changes. Moreover, these effects need to be disentangled from observed inputs and outputs in two time periods belonging to different decision making units: the pre-merger situation, where only the independent predecessor firms exist, and the post-merger situation, where only the merged company operates while the predecessor firms do not exist anymore. In addition, as comparability of productivity growth rates with non-merging firms is still relevant, a merger consistent decomposition of the productivity change should also provide results that are consistent with standard decomposition techniques in the absence of a merger.

Inspired by Bogetoft and Wang (2005), we propose an adaptation of the Malmquist index that allows for a detailed analysis of a merger's effect on productivity change. We illustrate this decomposition by analyzing the wave of mergers of Japanese water supply systems that occurred during the Great Heisei Era consolidation in the years after 2003. The assessment of the merger impact on productivity is particularly relevant in the water industry, which in many countries has been facing consolidation efforts to exhaust potential economies of scale in water supply. Therefore, our analysis allows a useful tool to identify the contribution of past mergers to productivity growth, thereby better informing policy makers with regard to whether and how consolidation has improved productivity performance of already merged firms. Furthermore, as the suitability of promoting further consolidation of Japan's still highly fragmented water industry remains as a major policy issue in the public debate on the restructuring reforms of the water industry (Urakami, 2019), improved understanding of how past mergers impact productivity can also help inform future policy decisions.

While we illustrate our methodology with water industry data, we emphasize that it should be widely applicable to any study where Malmquist productivity indices are applied, and researchers who wish to better understand how mergers have influenced productivity growth. Thus, while merger cases have been previously analyzed in a framework using Malmquist productivity growth indices, such studies usually compare the productivity growth of merger and non-merger firms for an evaluation of the merger impact. Examples are, among many others, Haneda et al. (2012) for mergers of Japanese municipal governments, Ferrier and Valdmanis (2004) for US hospitals; Grifell-Tatjé and Lovell (1997a), Sherman and Rupert (2006) and Tortosa-Ausina et al (2008) for banking, or Odeck (2008) on mergers in Norwegian public transport. However, none of these studies considers an explicit merger effect in the decomposition of the Malmquist productivity growth index, thereby suggesting the wide potential applicability of our methodology to future research in many industries.

The paper is structured as follows. Section 2 proposes an alternative decomposition of the Malmquist productivity index for merger analysis. Section 3 provides a brief background of the Japanese water industry context and reviews the related literature on water industry efficiency and productivity 
growth in the context of mergers. Section 4 focuses on the empirical estimation strategy. Section 5 describes the data sample on Japanese water utilities used for our analysis. Results are presented in Section 6, and Section 7 concludes.

\section{Measuring and decomposing productivity change in the presence of mergers}

\subsection{Details of the underlying merger consistent notation}

For ease of exposition, let us consider two independent pre-merger companies, $A$ and $B$, which are only observed in period 0 , and merge into a new company $M$, which is observed in period 1 only. ${ }^{2}$ Company $A$ uses the input vector $x_{A}$ to produce the output vector $y_{A}$ and company $B$ equivalently uses inputs $x_{B}$ to produce output vector $y_{B}$. To allow for the merger, the observed data for the two predecessor firms $A$ and $B$ can be aggregated into a hypothetical new company $(A D D)$ using the observed aggregated quantity of inputs $x_{A D D}=x_{A}+x_{B}$ to produce the observed aggregate output vector $y_{A D D}=y_{A}+y_{B}$. Correcting for individual inefficiencies of the pre-merger companies, the efficient individual input quantities $x_{A}^{0 *}$ and $x_{B}^{0 *}$ under period 0 variable returns to scale (VRS) technology can be aggregated to obtain the input quantities $\tilde{x}_{A D D}^{0}=x_{A}^{0 *}+x_{B}^{0 *}$ of the efficient additive company, thereby reflecting additive efficient input quantities in the pre-merged production structure present in period 0 . The same approach of correcting predecessor firms for individual inefficiencies has been proposed by Bogetoft and Wang (2005) for the calculation of and ex-ante assessment of the corrected potential overall gains from a merger.

In period 1 , only the merged company $M$, using inputs $x_{M}$ to produce outputs $y_{M}$, is observed.

For the purpose of decomposing productivity change between the merging individual predecessor companies observed in period 0 and the merged company observed in period 1 , we additionally define the efficient additive company $A D D^{l}$ using inputs $\tilde{x}_{A D D}^{1}=x_{A}^{1 *}+x_{B}^{1 *}$ to produce the same amount of output $y_{A D D}=y_{A}+y_{B}$, where $x_{A}^{1 *}$ and $x_{B}^{1 *}$ denote the efficient input quantities of the predecessor companies $(A$ and $B)$ relative to the period 1 VRS technology. ${ }^{3}$ While our decomposition is feasible in

\footnotetext{
${ }^{2}$ While we maintain focus on a two firm case in the main text for ease of exposition, our methodology is generalisable for mergers between any number of predecessor fiirms. Thus, our below analysis applies our decomposition to 17 merging cases with more than 2 predecessor firms, and should be seen as an extension of the approach employed by Bogetoft and Wang (2005) and Zschille (2015).

${ }^{3}$ The computation of the efficiency scores for the additive firms is done without including them in the reference set because they may not belong to the variable returns to scale (VRS) technology. We note that to allow every additive firm to be evaluated against a VRS frontier, the sample must include sufficiently large peers for benchmarking all the mergers. In other words, infeasibility occurs when the additive firm exceeds the largest firm in the sample, and thereby it cannot be projected onto the frontier formed by the observed firms. In practice, given the excellent source of data and wide range of firm scales in our empirical application, we have not faced such infeasibility issues in our below application.
} 
a multiple output multiple input context, Figure 1 depicts all these points in the single output-single input case for ease of exposition. ${ }^{4}$

Figure 1. TFP change decomposition in the presence of a merger

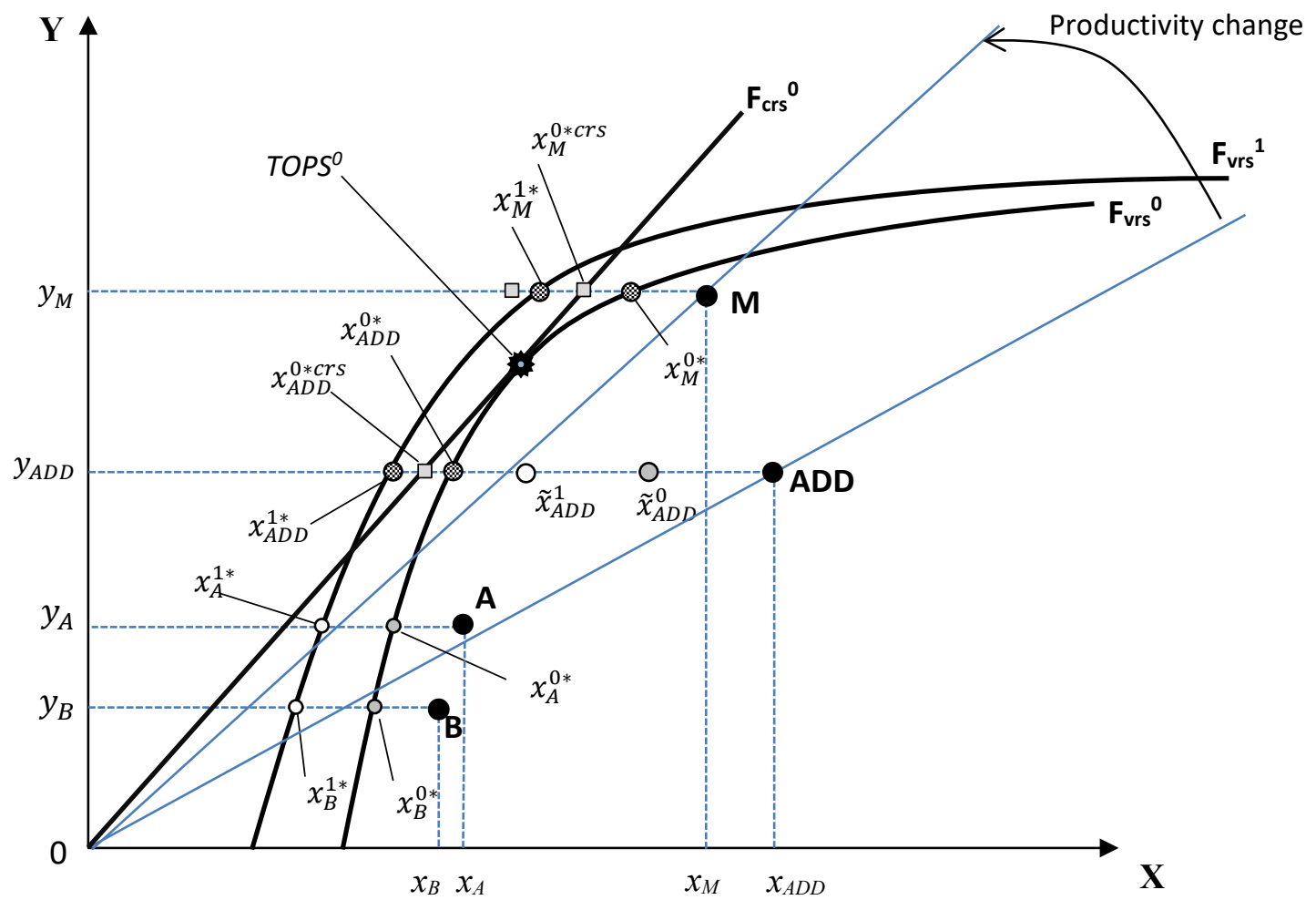

We can easily illustrate the applicability of the underlying notation to case when a merger does not occur by assuming that firm $B$ does not exist, and assuming that in this situation firm $A$ is an observed firm in period 0 while firm $M$ is the same firm observed in period 1 . Given our notation, this is equivalent to assuming that all quantities for firm $B$ are zero, and particularly that $x_{B}=0$ and $y_{B}=0$.

Therefore, in period 0 observed (pre-merger) firm $A$ uses $x_{A}$ to produce output $y_{A}$, and as no merger will occur, firm $B$ is assumed to have zero inputs and outputs. Thus, we can still construct an additive firm $A D D$, but the observed data for the additive firm is identical to that for firm $A$. e.g. $x_{A D D}=$ $x_{A}$ is used to produce $y_{A D D}=y_{A}$. As defined above $x_{A}^{0 *}$ is the efficient input requirement vector of firm A in period 0 , i.e. the minimum input consumption to produce the given output $y_{A}$. As $y_{B}=0, x_{B}^{0 *}$ will also be zero, as must be the case if outputs are zero. Under these assumptions, the efficient additive firm $\widetilde{A D D}^{0}$ would use $\tilde{x}_{A D D}^{0}=x_{A}^{0 *}$ to produce $y_{A D D}=y_{A}$.

\footnotetext{
${ }^{4}$ For ease of expositon the predecessor firms A and B, and their aggregation ADD, which are only empirically observable in period 0 , and the merged firm $\mathrm{M}$, which is only observable in period 1 , indicated in bold with observable quantities labelled on the axes of Figure 1. In contrast, relevant frontier reference points, required to illustrate the single output-single input decomposition, are indicated via identifying the relevant point on the froniters with labels that represent theefficient input quantity associated with these points. Similarly, $\tilde{x}_{A D D}^{0}$ and $\tilde{x}_{A D D}^{1}$ reflect the efficient additive technology in period 0 and period 1 for producing the output qantity $y_{A D D}$.
} 
Given our notation, in period 1 we only observe a single firm $M$, regardless of whether a merger has occurred, and its input usage is $x_{M}$ and output is $y_{M}$. However, this firm is not the result of a merger. Instead, firm $M$ is the continuation of firm A, which may have experienced some degree of organic/nonmerger related growth and technical change.

We can again go through the process of constructing an additional efficient additive firm in period $1\left(\widetilde{A D D}^{1}\right)$ in the absence of a merger. To that end, we first calculate the efficient input consumption of the original firms, $A$ and $B$, to separately produce respectively $y_{A}$ and $y_{B}$ as if they were operating under period 1 technology (e.g. by projecting the original units onto the period 1 frontier). We denote these firms as $\tilde{A}^{1}$ and $\tilde{B}^{1}$. However, given the assumption that $y_{B}=0$, firm $\tilde{A}^{1}$ would use $x_{A}^{1 *}$ to produce $y_{A}$ while firm $\tilde{B}^{1}$ would use $x_{B}^{1 *}=0$ to produce $y_{B}=0$. That is, in the absence of a merger, the efficient additive firm $\widetilde{A D D}^{1}$ would have $\tilde{x}_{A D D}^{1}=x_{A}^{1 *}$ to produce the same level of output as $\widetilde{A D D}^{0}$, $y_{A D D}=y_{A}$. Given this restatement of the underlying data in the absence of a merger, we can now turn to our productivity decomposition and its interpretation in the case when mergers do and do not occur.

\subsection{A merger consistent Malmquist productivity change decomposition}

The technology for period $s$ is represented by the set $T^{s}=\left\{\left(x^{S}, y^{s}\right): y^{s}\right.$ can be produced by $\left.x^{S}\right\}$, where $x$ and $y$ respectively are the input and output vectors at time $s$. The output distance function for a point $(x, y)$ is defined as $D_{o}^{s}\left(y^{s}, x^{s}\right)=\min \left\{\delta:\left(x^{s}, \frac{y^{s}}{\delta}\right) \in T^{s}\right\}$, and the input distance function is defined as $D_{i}^{s}\left(y^{s}, x^{s}\right)=\max \left\{\theta:\left(\frac{x^{s}}{\theta}, y^{s}\right) \in T^{s}\right\}$. Introducing observations from two periods, $t$ and $t+1$, and the corresponding technology sets $T^{t}$ and $T^{+1}$, following Caves et al (1982), the Malmquist productivity index is defined as the ratio of two distance functions:

$$
M_{g}^{S}\left(y^{t+1}, x^{t+1}, y^{t}, x^{t}\right)=\frac{D_{g}^{S}\left(y^{t+1}, x^{t+1}\right)}{D_{g}^{S}\left(y^{t}, x^{t}\right)}, s=t, t+1, g=o, i
$$

That is, the Malmquist productivity index can be output oriented $(g=o)$ or input oriented $(g=$ $i$ ), as well as either take the technology of period $t(s=t)$ or the technology of period $t+1(s=t+1)$ as a base.

We recall here that the output distance function is equivalent to the Farrell (1957) output efficiency measure, $E_{o}(y, x)$, while the input distance function corresponds to the reciprocal of the Farrell input efficiency measure $E_{i}(y, x)$. Thus, $D_{o}(y, x)=E_{o}(y, x)$ and $D_{i}(y, x)=\frac{1}{E_{i}(y, x)}$.

In the following we will use the efficiency measure notation instead of the notation based on distance functions. As Bjurek et al (1998) note, the advantage of expressing the Malmquist index by the Farrell efficiency measures is that the output and input based index expressions are symmetric. That is, either under an output or an input orientation a value of $M$ greater than one indicates productivity improvement and less than one productivity decline. Thus, using the basic notation of the previous section, a Malmquist productivity change index (hereafter MPI) between the observed additive 
quantities of the predecessor firms in period 0 and observed quantities for the merged firm in period 1 , and referring to the period 0 technology, is defined as:

$$
M P I=M\left(y_{A D D}, x_{A D D}, y_{M}, x_{M}\right)=\frac{E_{c r s}^{0}\left(y_{M}, x_{M}\right)}{E_{c r s}^{0}\left(y_{A D D}, x_{A D D}\right)}
$$

with $E_{C R S}^{0}(y, x)$ denoting the efficiency score obtained under the assumption of constant returns to scale (CRS) relative to the period 0 technology. The Malmquist index in (2) measures the productivity change from the additive observation created from the individual predecessor firms observed in period 0 to the merged firm observed in period 1. Figure 1 also illustrates the case for observed productivity growth as reflected by the increase in the slope of the ray from the origin through points $A D D$ in period 0 and $M$ in period 1.

We suggest that a merger consistent decomposition of (2) can be defined as follows:

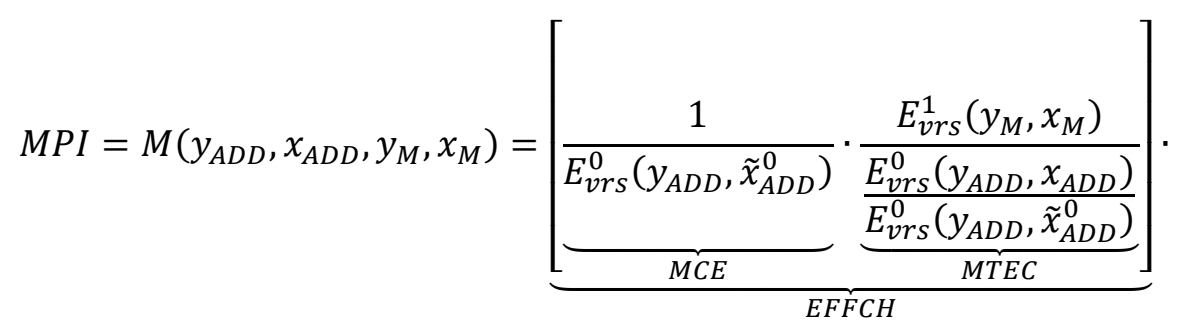

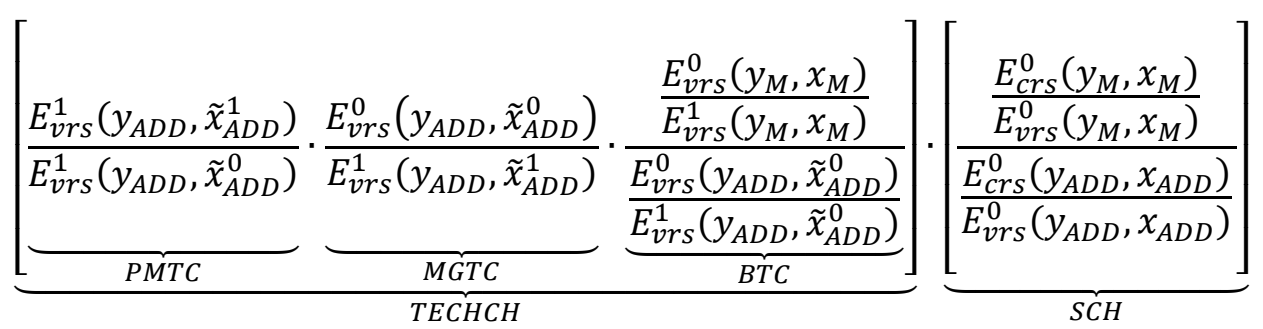

A substantial number of alternative decompositions of (2) aimed at better identifying the sources of productivity growth have been developed in the literature (e.g. Färe et al. 1994; Ray and Desli, 1997; Grifell-Tatjé and Lovell, 1999; Lovell, 2003). ${ }^{5}$ In any case, while researchers may disagree about which of these decompositions is more appropriate, our approach is applicable to all these decompositions. Thus, we note that the six components of the decomposition of productivity change shown in (3) can be clustered into three indexes measuring technical efficiency change (EFFCH), technical change (TECHCH) and scale change effect ( $\mathrm{SCH}$ ), in a way that is consistent with the original Ray and Desli's (1997) decomposition of a Malmquist index with period 0 technology as a base.

We now consider each of the components of (3). We note that while each component is defined and appropriate regardless of the number of inputs and outputs, for ease of exposition we also illustrate the decomposition for the single input and single output case already illustrated in Figure 1. In (3) the technical efficiency change component $(\mathrm{EFFCH})$ has been decomposed into two separate indexes:

\footnotetext{
${ }^{5}$ See Lovell (2003) and Zofío (2007) for a comprehensive analysis of such approaches. Zofío (2007) usefully illustrates the multiplicative equivalence and links between these alternative decompositions.
} 


$$
E F F C H=\left[\frac{1}{E_{v r s}^{0}\left(y_{A D D}, \tilde{x}_{A D D}^{0}\right)}\right] \cdot\left[\frac{E_{v r s}^{1}\left(y_{M}, x_{M}\right)}{\frac{E_{v r s}^{0}\left(y_{A D D}, x_{A D D}\right)}{E_{v r s}^{0}\left(y_{A D D}, \tilde{x}_{A D D}^{0}\right)}}\right]=M C E \cdot M T E C
$$

Note that for merged firms the (in)efficiency of $A D D$ in the denominator of EFFCH in (2) is evaluated with additive quantities but assuming merged production, and therefore is measured against a benchmark point in the frontier that is not feasible for the predecessor non-merged firms. Thus, direct application of the standard approach would falsely aggregate actual technical efficiency change achieved during the merger period with the size-related consolidation economies associated with the merger.

The first bracketed term in (4) represents the direct impact of merger consolidation on productivity growth, defined as the reciprocal of the efficiency of the additive efficient firm relative to the period 0 variable returns to scale frontier. More precisely, the merger consolidation effect (MCE) quantifies the gains resulted from the merger of the observed (pre-merged) individual firms (without considering any further change in the scale of operations after the merger), and thereby provides an estimate of the direct impact of the merger net of any difference in realized technical change between the predecessor firms and the merged firms. Basically, the MCE results from the aggregation of the existing predecessor firms, and indicates the gains resulting from joint versus separate production. Our merger effect is therefore the exact inverse of the corrected potential merger gain measure proposed by Bogetoft and Wang (2005) ${ }^{6}$. In Figure 1 the MCE is measured as:

$$
M C E=\frac{1}{E_{v r S}^{0}\left(y_{A D D}, \tilde{x}_{A D D}^{0}\right)}=\frac{1}{x_{A D D}^{0 *} / \tilde{x}_{A D D}^{0}}
$$

If greater than 1, as in Figure 1, it reflects the fact that the separate production of $y_{A D D}$ in two independent (and individually efficient) firms, one producing output quantity $y_{A}$ and the other one producing $y_{B}$, is not the most efficient way of producing the total output $y_{A D D}$. The merger consolidation effect is always greater than one when the production technology is superadditive. ${ }^{7}$ As the reader should expect, the merger consolidation effect will be equal to one in the absence of a merger. Thus, if no merger occurs, (5) can be restated as follows:

$$
M C E=\frac{1}{E_{v r s}^{0}\left(y_{A D D}, \tilde{x}_{A D D}^{0}\right)}=\frac{1}{E_{v r s}^{0}\left(y_{A}, x_{A}^{0 *}\right)}=\frac{1}{x_{A}^{0 *} / x_{A}^{0 *}}=1
$$

\footnotetext{
${ }^{6}$ We note that Bogetoft and Wang (2005) focus on a static context in a single pre-merger period. Thus, as their methodological approach is designed for analyzing the potential benefits of mergers with cross sectional data, they cannot consider the potential effects of technical change and/or changes in the output scale in subsequent periods.

${ }^{7}$ i.e. if $\mathrm{F}\left(\mathrm{x}_{\mathrm{A}}+\mathrm{x}_{\mathrm{B}}\right)>\mathrm{F}\left(\mathrm{x}_{\mathrm{A}}\right)+\mathrm{F}\left(\mathrm{x}_{\mathrm{B}}\right)$ then the MCE is positive. In contrast, the scale effect (SCH as defined in equation 3 , and discussed below) results from a post merger change in the scale of operations of the additive firm, i.e. it is positive if $\mathrm{F}\left(\mathrm{x}_{\mathrm{M}}\right)=\mathrm{F}\left(\mathrm{k}\left(\mathrm{x}_{\mathrm{A}}+\mathrm{x}_{\mathrm{B}}\right)\right)>\mathrm{kF}\left(\mathrm{x}_{\mathrm{A}}+\mathrm{x}_{\mathrm{B}}\right)$, with $\mathrm{k}>0$. Thus, as Ray $(2004, \mathrm{p} .189)$ notes, "the sub/superadditivity properties of the technology are closely related to but are at the same time subtly different from its returns to scale properties". Further, it is easy to show that the prevalence of increasing returns at the two predecessor firms' input levels is not a necessary condition for obtaining a positive merger consolidation effect (Ray 2004, p. 191).
} 
The second component in (4) is a merger consistent technical efficiency change effect (MTEC), which is constructed in a manner that the efficiency of the observed predecessor firms is compared to that of the observed merged firm. In Figure 1 this is given by the comparison of the horizontal separation between points $x_{M}$ and $x_{M}^{1 *}$ and the horizontal separation between $x_{A D D}$ and $\tilde{x}_{A D D}^{0}$, i.e.

$$
M T E C=\left[\frac{E_{v r s}^{1}\left(y_{M}, x_{M}\right)}{\frac{E_{v r s}^{0}\left(y_{A D D}, x_{A D D}\right)}{E_{v r s}^{0}\left(y_{A D D}, \tilde{x}_{A D D}^{0}\right)}}\right]=\frac{x_{M}^{1 *} / x_{M}}{\frac{x_{A D D}^{0 *} / x_{A D D}}{x_{A D D}^{0 *} / \tilde{x}_{A D D}^{0}}}
$$

where $x_{M}^{1 *}$ is the minimum (efficient) input quantity to produce $y_{M}$. In other words, the efficiency change component compares the technical efficiency of the merged firm with the efficiency of the additive firm, the latter being measured so as to appropriately aggregate the individual inefficiencies of the predecessor firms in the base period. Consideration of technical efficiency change in this manner is highly relevant, as improved management in larger organizations is often provided as a justification for mergers.

In the absence of a merger, MTEC can be restated as follows:

$$
M T E C=\left[\frac{E_{v r s}^{1}\left(y_{M}, x_{M}\right)}{\frac{E_{v r s}^{0}\left(y_{A D D}, x_{A D D}\right)}{E_{v r s}^{0}\left(y_{A D D}, \tilde{x}_{A D D}^{0}\right)}}\right]=\left[\frac{E_{v r s}^{1}\left(y_{M}, x_{M}\right)}{\frac{E_{v r s}^{0}\left(y_{A}, x_{A}\right)}{E_{v r s}^{0}\left(y_{A}, x_{A}^{0 *}\right)}}\right]=\left[\frac{E_{v r s}^{1}\left(y_{M}, x_{M}\right)}{E_{v r s}^{0}\left(y_{A}, x_{A}\right)}\right]=\frac{x_{M}^{1 *} / x_{M}}{x_{A}^{0 *} / x_{A}}
$$

and thus, reverts exactly to the standard technical efficiency change (EFFCH) productivity decomposition component.

The TECHCH component in the standard Malmquist decomposition (2) is the technical change between periods 0 and 1, measured along a ray through period 1 data. Following Färe et al (1997), this technical change index can be expressed as the product of a magnitude index and a bias index:

$$
T E C H C H=\left[\frac{E_{v r s}^{0}\left(y_{M}, x_{M}\right)}{E_{v r s}^{1}\left(y_{M}, x_{M}\right)}\right]=\left[\frac{E_{v r s}^{0}\left(y_{A D D}, \tilde{x}_{A D D}^{0}\right)}{E_{v r s}^{1}\left(y_{A D D}, \tilde{x}_{A D D}^{0}\right)}\right] \cdot\left[\frac{\frac{E_{v r s}^{0}\left(y_{M}, x_{M}\right)}{E_{v r s}^{1}\left(y_{M}, x_{M}\right)}}{\frac{E_{v r s}^{0}\left(y_{A D D}, \tilde{x}_{A D D}^{0}\right)}{E_{v r s}^{1}\left(y_{A D D}, \tilde{x}_{A D D}^{0}\right)}}\right]=T C 0 \cdot B T C
$$

The first term in (9) measures the magnitude of technical change along a ray through period 0 data (TC0). The magnitude index measures the relative distance between the period 1 frontier and the period 0 frontier at the period 0 observation, using period 0 data to compare the two production frontiers. This term provides a local measure of the magnitude of technical progress or technical regress.

The second component of TECHCH in (9) is the bias of technical change (BTC), which captures the difference in the rate of technical change between additive period 0 quantities and period 1 observed post-merger quantities. That is, it is measured as the ratio of the magnitude of technical change evaluated at merged firm data to the magnitude of technical change evaluated at additive firm data. The bias index measures the change in the relative distance between the two frontiers between the post-merged observation and the additive (pre-merged) observation. The BTC index makes no contribution to productivity change if the magnitude of technical change is the same when measured along the two observations. The contribution is positive (negative) when the magnitude of technical change measured 
at merged data exceeds (falls short of) the magnitude of technical change measured at additive data. If technical change is neutral, the production set shifts out by the same proportion along a ray through period 1 data as it does along a ray through period 0 data. Consequently, the two magnitudes are identical, and the BTC attains a value of unity. On the contrary, if technical change is biased, the production set shifts out by a different proportion along a ray through period 1 data than it does along a ray through period 0 data. As Grifell-Tatjé and Lovell (1997b) argue, the bias term can be interpreted as an indicator of managerial adaptation to changing technology. That is, it makes a positive (negative) contribution to productivity change as management adjusts production in the right (wrong) direction when confronted with a non-neutral change in production possibilities.

In the absence of mergers BTC can be restated and recognized as a standard measure of bias in technical change measured as the ratio of technical change measured at period 1 output quantities relative to technical change measured at period 0 quantities:

$$
B T C=\frac{\frac{E_{v r s}^{0}\left(y_{M}, x_{M}\right)}{E_{v r s}^{1}\left(y_{M}, x_{M}\right)}}{\frac{E_{v r s}^{0}\left(y_{A D D}, \tilde{x}_{A D D}^{0}\right)}{E_{v r s}^{1}\left(y_{A D D}, \tilde{x}_{A D D}^{0}\right)}}=\frac{\frac{E_{v r s}^{0}\left(y_{M}, x_{M}\right)}{E_{v r s}^{1}\left(y_{M}, x_{M}\right)}}{\frac{E_{v r s}^{0}\left(y_{A}, x_{A}^{0 *}\right)}{E_{v r s}^{1}\left(y_{A}, x_{A}^{0 *}\right)}}
$$

Note that in our merger consistent decomposition (3) we have further decomposed the magnitude of the technical change index (TC0) as:

$$
T C 0=\left[\frac{E_{v r s}^{1}\left(y_{A D D}, \tilde{x}_{A D D}^{1}\right)}{E_{v r s}^{1}\left(y_{A D D}, \tilde{x}_{A D D}^{0}\right)}\right] \cdot\left[\frac{E_{v r s}^{0}\left(y_{A D D}, \tilde{x}_{A D D}^{0}\right)}{E_{v r s}^{1}\left(y_{A D D}, \tilde{x}_{A D D}^{1}\right)}\right]=P M T C \cdot M G T C
$$

The first component in (11) above provides a merger consistent estimate of technical change at period 0 output quantities while accounting for the pre-merger structure of production. We label this as Pre-Merger Technical Change (PMTC). PMTC accounts for productivity change due to shifts in the best practice technology that the constituents firms of the merger would have attained if they had remained separate instead of merged. It is measured by the ratio of the efficiency of the two efficiency-adjusted additive firms with respect to period 1 frontier. In Figure 1 below it is shown by the horizontal separation between $\tilde{x}_{A D D}^{1}$ and $\tilde{x}_{A D D}^{0}$.

The second component in (11) is the Merger Gap Technical Change effect (MGTC), and measures the change between period 0 and period 1 in the productivity gap that exists between the efficient production of output $y_{A D D}$ when it is either produced separately in the two existing firms or within a single additive firm. It is similar to the 'Best Practice Gap Change' component defined by Pastor and Lovell (2005) and Pastor et al (2011). ${ }^{8}$ Referring to Figure 1, The MGTC is expressed as:

\footnotetext{
${ }^{8}$ This similarity can be further shown by noting that MGTC can be equivalently stated as: $M G T C=\frac{E_{v r s}^{0}\left(y_{A D D}, \tilde{x}_{A D D}^{0}\right) / E_{v r S}^{+0}\left(y_{A D D}, \tilde{x}_{A D D}^{0}\right)}{E_{v r s}^{1}\left(y_{A D D}, \tilde{x}_{A D D}^{1}\right) / E_{v r s}^{+1}\left(y_{A D D}, \tilde{x}_{A D D}^{1}\right)}$, where superscript + refers to the hypothetical additive technology, and noting that by construction of $\tilde{x}_{A D D}^{0}$ and $\tilde{x}_{A D D}^{1}, E_{v r s}^{+1}\left(y_{A D D}, \tilde{x}_{A D D}^{1}\right)=E_{v r s}^{+0}\left(y_{A D D}, \tilde{x}_{A D D}^{0}\right)=1$
} 


$$
M G T C=\frac{E_{v r s}^{0}\left(y_{A D D}, \tilde{x}_{A D D}^{0}\right)}{E_{v r s}^{1}\left(y_{A D D}, \tilde{x}_{A D D}^{1}\right)}=\frac{x_{A D D}^{0 *} / \tilde{x}_{A D D}^{0}}{x_{A D D}^{1 *} / \tilde{x}_{A D D}^{1}}=\frac{x_{A D D}^{0 *} / x_{A D D}^{1 *}}{\tilde{x}_{A D D}^{0} / \tilde{x}_{A D D}^{1}}
$$

MGTC in (11) indicates whether the separate production in period 1 is closer to (or farther away) from the best practice merging benchmark than in period 0 , i.e. the ratio of technical change of the efficient additive firm relative to the efficient predecessor firms. This illustrates that when MGTC exceeds (is below) one, technical progress that would have been achievable after the merger exceeds (is below) that which is achievable in the absence of the merger.

When considering (12) in the absence of mergers MGTC becomes redundant, as we should expect. Thus, in the absence of a merger it can be restated as:

$$
M G T C=\frac{E_{v r s}^{0}\left(y_{A D D}, \tilde{x}_{A D D}^{0}\right)}{E_{v r s}^{1}\left(y_{A D D}, \tilde{x}_{A D D}^{1}\right)}=\frac{E_{v r s}^{0}\left(y_{A}, x_{A}^{0 *}\right)}{E_{v r s}^{1}\left(y_{A}, x_{A}^{1 *}\right)}=1
$$

We finally consider the sixth component in brackets in our merger consistent decomposition (3), which captures a post-merger scale change effect ( $\mathrm{SCH})$. That is, it measures the change in the scale efficiency-i.e. the distance to the technically optimal scale point (in Figure 1 labeled as TOPS) between pre-merger and post-merger quantities. In Figure 1 the $S C H$ would be computed as:

$$
S C H=\left[\frac{\frac{E_{c r s}^{0}\left(y_{M}, x_{M}\right)}{E_{v r s}^{0}\left(y_{M}, x_{M}\right)}}{\frac{E_{c r s}^{0}\left(y_{A D D}, x_{A D D}\right)}{E_{v r s}^{0}\left(y_{A D D}, x_{A D D}\right)}}\right]=\left[\begin{array}{l}
\frac{x_{M}^{0 * c r s}}{x_{M}^{0 *}} \\
\frac{x_{A D D}^{0 * c r s}}{x_{A D D}^{0 *}}
\end{array}\right]
$$

And in the absence of a merger can be restated as a standard scale change affect:

$$
S C H=\left[\frac{\frac{E_{c r s}^{0}\left(y_{M}, x_{M}\right)}{E_{v r s}^{0}\left(y_{M}, x_{M}\right)}}{\frac{E_{c r s}^{0}\left(y_{A D D}, x_{A D D}\right)}{E_{v r s}^{0}\left(y_{A D D}, x_{A D D}\right)}}\right]=\frac{\frac{E_{c r s}^{0}\left(y_{M}, x_{M}\right)}{E_{v r s}^{0}\left(y_{M}, x_{M}\right)}}{\frac{E_{c r s}^{0}\left(y_{A}, x_{A}\right)}{E_{v r s}^{0}\left(y_{A}, x_{A}\right)}}=\left[\frac{\frac{x_{M}^{0 *}(r s}{x_{M}^{0 *}}}{\frac{x_{A}^{0 * c r s}}{x_{A}^{0 *}}}\right]
$$

\section{Background: mergers and consolidation in the water supply industry}

As is the case in other developed countries such as the Netherlands and The United Kingdom, water supply in Japan has become more consolidated in the past two decades. However, in Japan where water supply is generally provided by quasi-independent public companies with boundaries consistent with municipalities, this consolidation has largely been driven by the Japanese central government's policy of encouraging the consolidation of relatively small local administrative authorities like municipalities or smaller villages into larger units.

Thus, information provided by the Ministry of Internal Affairs and Communications indicates that the number of municipalities decreased from 3,232 to 1,718 between 1999 and 2014, and these municipal consolidations have often resulted in a subsequent consolidation of water utilities. Large water supply (LWS) systems serving a population of more than 5,000 people require licensing from the Ministry of Health, Labor and Welfare, while other public small water supply (SWS) systems are licensed by the responsible prefecture governments (MHLW, 2017). Private operations are possible 
through approval by the responsible local government, but there are currently only nine privately owned water utilities in Japan. Even after a process of considerable municipal consolidation, public water supply is still highly fragmented due to organization at the municipal level ${ }^{9}$. Thus, in 2015 , there were still 1,381 LWS utilities supplying water to at least 5,001 inhabitants and 5,629 SWS systems supplying water to less than 5,001 inhabitants. In addition, 92 bulk water supply companies were active in wholesale water production. Those bulk water supply companies usually are owned jointly by different municipalities or prefecture governments (MHLW, 2017). However, the extent of water industry consolidation as a result of municipal consolidation is evident by comparing the 2015 numbers to the 8,979 SWS, 1,958 LWS and 111 bulk water suppliers that existed in 2000

Looking forward and despite the consolidation that has already occurred, the still fragmented Japanese water industry faces two simultaneous and formidable challenges. Firstly, the need for considerable investment to replace, maintain, and/or repair ageing facilities, most of which were built in the 1950s and 1960s. ${ }^{10}$ Secondly, Japan's population is already decreasing, and it is expected to suffer dramatic further decline in the next decades. Thus, the National Institute of Population and Social Security Research (NIPSSR, 2017) estimates that the total population will decline from 127 million in 2015 to 88 million in 2065 under medium mortality and fertility assumptions. ${ }^{11}$ Consequently, this scenario projects a sharp drop in population and hence water demand over the next decades. Such potential population decline is also likely to substantially reduce the Japanese economy's potential to fund the investment required to maintain water infrastructure.

In this context, it is also important to highlight that as the majority of water companies remain very small, serving less than 5,000 inhabitants, further financial limitations for the needed investment and funding plans to replace pipelines and water treatment facilities will exist. Likewise, small water companies also face considerable difficulties in hiring and maintaining access to needed technical staff e.g. engineers, chemists (Nikkei, 2019).

Given this brief description of the current context, it is our understanding that the Japanese government believes that further consolidation of the water industry is required. In essence, the consolidation process would lead to the creation of larger companies better able to face the challenges referred to above. In particular, this would potentially avoid the duplication that would occur if small water systems reconfigured and renewed existing pipe networks and water purification plants, without coordinating with neighboring systems. Thus consolidation is likely to allow a widespread and shared use of water facilities, and to potentially facilitate the adoption of the so called 'private sector style management schemes' (Minkanteki Keiei Syuho) in municipal utilities (Mizutani 2012).

\footnotetext{
${ }^{9}$ See Mizutani (2012) for a more comprehensive analysis of the organization, regulation and structural reforms in the water supply industry in Japan.

${ }^{10}$ As Japan is particularly susceptible to natural disasters (e.g. earthquakes and typhoons) that typically cause serious damage to water industry infrastructure, investment needs are particularly high, and climate change is likely to exacerbate the potential for such serious damage.

${ }^{11}$ Under the high mortality and low fertility scenario the projected population could drop to 80 million in 2065 .
} 
Focusing specifically on the benefits of consolidating the water industry, the Japanese Water Works Association identified a number of dimensions that would potentially improve as a result of the water utility mergers (JWWA, 2004). Such potential benefits were clustered into five general categories, as shown in Table 1, and summarize the main direct and indirect effects expected from mergers in the water industry. Subsequently Urakami (2008) reports the results of a representative survey of planning and development managers involved in Japanese water industry consolidation, in order to identify which of the JWWA's potential benefits of mergers were actually considered to be significant by water managers. The author shows that $46 \%$ of the responding managers believed that mergers would save operating costs, though only around $25 \%$ of them believed that such gains would be substantial.

Nevertheless, there has been very little economic analysis of the realized benefits of water industry consolidation. While the empirical literature provides a high number of studies on economies of scale in water supply, see Saal et al. (2011) for a review of the literature, there are only a few studies focusing on the analysis of efficiency and productivity gains from mergers in water supply.

\section{Table 1. Potential Benefits of Water Utility Merger}

\begin{tabular}{l} 
Water supply and demand \\
Balancing water demand and supply between LWSs \\
Joint development of water sources \\
Promotion of stable supply with multiple water sources \\
\hline Facilities \\
Implement new technologies for treatment plants and pipelines \\
Renewal of aging facilities and pipelines \\
\hline Operation and maintenance \\
Increase the number of technical staff \\
Improvement of technical capabilities \\
Enhancement of water quality management \\
Enhancement of maintenance management \\
Enhancement of operation management \\
Prevention of accident \\
\hline Finance \\
Strengthening of the financial base \\
Saving of construction investment \\
Saving of operating cost (labor cost, etc.) \\
\hline Service \\
Decreasing the unsupplied area \\
Reducing the price difference \\
Unifying the method of water tariff collection \\
Prevention of water leakage/water outage \\
Strengthening of emergency water supply system
\end{tabular}

Source: JWWA (2004)

For the case of Japan, Urakami and Parker (2011) estimate a translog total cost function with hedonic output specification for an unbalanced panel with a total of 13,811 observations between 1999 and 2006. By including a consolidation dummy variable in the cost function, they find a positive but 
weak impact of consolidation on the cost efficiency of merged firms. Compared to non-merger companies, consolidation has led to slower increases in the cost of water supply. Even after consolidation, the results indicate the existence of economies of scale, such that further consolidation might be beneficial. The methodological approach of Urakami and Parker (2011) including a trend shift variable in the cost function however does not allow for a detailed analysis of merger gains and its potential sources.

Based on the approach by Bogetoft and Wang (2005), Zschille (2015) investigates the potential efficiency gains that would result from a hypothetical consolidation in the German potable water sector. He concludes that efficiency improvement potentials for the water utilities result from technically more efficient operations rather than from mergers and corresponding changes in market structures. In the same vein, Abrate et al (2017), based on a parametric cost frontier analysis of the Bogetoft and Wang (2005)'s approach, analyze the potential benefits of a simulated process of consolidation of the Italian water and sewerage industry.

De Witte and Dijkgraaf (2010) analyze the Dutch drinking water sector based on a nonparametric order-m approach. They analyze the impact of voluntary benchmarking and mergers on efficiency. Efficiency impacts are illustrated using nonparametric regression plots. Voluntary benchmarking efforts of the industry resulted in increased efficiency of the water utilities. However, their results indicate no significant efficiency gains from consolidation, neither through an increase in the scale of operations, nor through better incentives for increasing efficiency. Further, their approach does not allow for a dynamic evaluation of consolidation and to disentangle the impact of merger on efficiency from other potential sources of efficiency improvements.

For the case of England and Wales, Stone \& Webster (2004) compare the cost function estimates between merged and non-merged water and sewerage companies (WaSC). Their results indicate no significant differences between the cost function estimates for both types of companies. However, this approach does not allow for a profound merger analysis in a dynamic efficiency framework and for the detection of potential sources of efficiency improvements.

Saal et al. (2007) focus on the estimation of Malmquist productivity growth indices for English and Welsh WaSCs over the period 1985-2000. Decomposing the overall productivity growth index into efficiency change, technical change and scale change components, they find negative scale effects over the entire sample period. Saal et al. (2007) argue that scale changes through consolidation have led to scale disadvantages and indicate diseconomies of scale for WaSCs. A further consolidation of the industry was thus not recommendable from a scale perspective. Saal et al. (2007) however does not focus on an explicit analysis of mergers in the English and Welsh water industry. Moreover, in the case of a merger, they follow a very common empirical practice by assuming the largest predecessor firm of a merged company as the reference observation for the estimation of productivity growth, thereby building in a systematic bias of the productivity impact of mergers, which should more correctly be evaluated by comparing the additive outputs and inputs of the predecessor firms to the merged firm. 
Thus, as with the previous Malmquist productivity index studies for other industries that we briefly summarized in the above introduction, previous water industry studies also do not provide a systematic decomposition of the productivity impacts of mergers. Our methodology should therefore allow policy makers in Japan to better understand how past water mergers impacted productivity, and thereby inform their considerations with how they might best encourage appropriate further consolidation.

\section{Estimation strategy}

The calculation of the Malmquist total factor productivity growth index and its decompositions requires the estimation of an underlying production technology. For each time period $t$, the technology is given by the production possibility set $T$, which summarizes the set of all feasible combinations of input and output vectors. It is defined as follows:

$$
T^{t}=\left\{(x, y) \in \mathbf{R}_{+}^{p+q}: x \text { can produce } y \text { in period } t\right\}
$$

where $x$ denotes a $p$-dimensional vector of inputs and $y$ a $q$-dimensional vector of outputs. For the empirical application we assume a non-parametric convex technology defined as:

$$
T(\gamma)=\left\{\begin{array}{c}
(x, y) \in \mathbf{R}_{+}^{p+q} \mid \exists \lambda \in \Lambda(\gamma): \sum_{k=1}^{K} \lambda_{k} x_{k j} \leq x_{j}(j=1, \ldots, p), \\
y_{i} \leq \sum_{k=1}^{K} \lambda_{k} y_{k i}(i=1, \ldots, q)
\end{array}\right\}
$$

where $\Lambda($ crs $)=\left\{\lambda \in \mathbf{R}_{+} \mid \sum_{k=1}^{K} \lambda_{k}\right.$ free $\}$, and $\Lambda($ vrs $)=\left\{\lambda \in \mathbf{R}_{+} \mid \sum_{k=1}^{K} \lambda_{k}=1\right\}$.

The distance functions for the estimation of the Malmquist index and its decomposition can be estimated by means of Data Envelopment Analysis (DEA). We assume an input orientation, thus considering the potential radial contraction in all inputs that allows to produce a given amount of outputs. The input-based Farrell efficiency relative to technology $T(\gamma)$ is defined as:

$$
E_{\gamma}^{k}(x, y)=\min \{\theta:(\theta x, y) \in T(\gamma)\}
$$

where $E_{\gamma}^{k}(x, y)$ denotes the efficiency score estimated for each observation in the sample, $k=1, \ldots, K$.

In addition to the estimation and decomposition of the Malmquist index, statistical inference with respect to the statistical significance of overall TFP growth and its components is of interest. For this purpose, Simar and Wilson (1999) propose a bootstrap approach to the estimation of confidence intervals for the overall Malmquist TFP growth index and its components, which is based on the original methodology suggested by Simar and Wilson (1998) for bootstrap approaches in the nonparametric DEA framework. Simar and Wilson (1999) argue that the true overall Malmquist TFP growth index $M$ and its decompositions are unknown and thus need to be estimated from the observed data sample $\chi$. In order to validate these estimators, we are interested in estimating a confidence interval of the form:

$$
\widehat{M}\left(y_{A D D}, x_{A D D}, y_{M}, x_{M}\right)+a_{\alpha} \leq M\left(y_{A D D}, x_{A D D}, y_{M}, x_{M}\right) \leq \widehat{M}\left(y_{A D D}, x_{A D D}, y_{M}, x_{M}\right)+b_{\alpha}
$$

with $\widehat{M}$ denoting the estimated Malmquist TFP growth index and $a_{\alpha}$ and $b_{\alpha}$ denoting the quantiles of the distribution $\widehat{M}\left(y_{A D D}, x_{A D D}, y_{M}, x_{M}\right)-M\left(y_{A D D}, x_{A D D}, y_{M}, x_{M}\right)$ according to

$$
\operatorname{Pr}\left(-b_{\alpha} \leq \widehat{M}\left(y_{A D D}, x_{A D D}, y_{M}, x_{M}\right)-M\left(y_{A D D}, x_{A D D}, y_{M}, x_{M}\right) \leq-a_{\alpha}\right)=1-\alpha
$$

e.g. with $\alpha=0.05$. 
Since the distribution of $\widehat{M}\left(y_{A D D}, x_{A D D}, y_{M}, x_{M}\right)-M\left(y_{A D D}, x_{A D D}, y_{M}, x_{M}\right)$ is unknown, Simar and Wilson (1999) suggest to obtain bootstrap estimates $\widehat{M}^{*}$ based on pseudo samples $\chi^{*}$ created from the original data to determine the approximate distribution $\widehat{M}^{*}\left(y_{A D D}, x_{A D D}, y_{M}, x_{M}\right)-$ $\widehat{M}\left(y_{A D D}, x_{A D D}, y_{M}, x_{M}\right)$. Quantile estimates $a_{\alpha}^{*}$ and $b_{\alpha}^{*}$ are obtained based on the bootstrap analogue of (19), of the form:

$$
\operatorname{Pr}\left(-b_{\alpha}^{*} \leq \widehat{M}^{*}\left(y_{A D D}, x_{A D D}, y_{M}, x_{M}\right)-\widehat{M}\left(y_{A D D}, x_{A D D}, y_{M}, x_{M}\right) \leq-a_{\alpha}^{*} \mid \chi\right)=1-\alpha
$$

The confidence interval for the overall Malmquist TFP growth index is then obtained by substituting the quantiles $a_{\alpha}$ and $b_{\alpha}$ in (18) by their bootstrap analogues and is defined as

$$
\widehat{M}\left(y_{A D D}, x_{A D D}, y_{M}, x_{M}\right)+a_{\alpha}^{*} \leq M\left(y_{A D D}, x_{A D D}, y_{M}, x_{M}\right) \leq \widehat{M}\left(y_{A D D}, x_{A D D}, y_{M}, x_{M}\right)+b_{\alpha}^{*}
$$

The same approach can be applied to estimate confidence intervals for each component of the Malmquist index decomposition. Estimated TFP growth or the components of the decomposition are statistically significant, e.g. at the $95 \%$ level, when the estimated confidence interval does not include the value of 1 (Simar and Wilson, 1999).

A crucial point in the estimation of confidence intervals in the productivity growth framework remains the choice of an appropriate bootstrap method to create the pseudo samples $\chi^{*}$. Simar and Wilson (1999) propose a smooth bootstrap approach based on a bivariate kernel density estimator to account for the panel structure of the data in productivity growth analyses. However, the Simar and Wilson (1999) approach is only applicable in balanced panel structures. Since our analysis is based on an unbalanced panel structure, it is therefore necessary to apply an alternative bootstrap approach to determine the pseudo samples $\chi^{*}$. For this purpose, we apply the subsampling bootstrap approach proposed by Simar and Wilson (2008, 2011). As Kneip et al. (2018) shows, the subsampling approach can be applied to estimate confidence intervals for individual firms' Malmquist indices even when a firm's input and output vector are dependent over time.

The subsampling approach is based on drawing $B$ times, e.g. $B=2000$, subsamples of size $m$ without replacement from the original sample of size $n$. For the determination of the value of $m$, we follow the procedure described by Simar and Wilson (2011). For the determination of the value of $m$ in the case of confidence intervals, Simar and Wilson (2011) recommend the estimation of multiple sets of confidence intervals for different values of $m$. The optimal value of $m$ is chosen as the value of $m$ that minimizes some volatility measure, in our case the volatility of the confidence intervals. Following Simar and Wilson (2011), we focus on the standard deviation of the bounds of the confidence intervals for different values of $m$ and we chose the value of $m$ that minimizes standard deviation. According to this procedure we select $m=450$. Given the focus on the object of interest (confidence intervals for the Malmquist indices and their components) we therefore choose one value of $m$ independent of the different sample sizes. 
All efficiency scores necessary for the estimation of the overall Malmquist TFP growth index and the components of its decomposition are estimated relative to this set of $B$ subsamples. ${ }^{12}$ Accordingly, $B$ sets of estimates of $M$ and its decomposition are estimated and used for the estimation of confidence intervals according to (20) and (21). Due to the application of the subsampling bootstrap approach, it is necessary to adjust bootstrap estimates of $a_{\alpha}^{*}$ and $b_{\alpha}^{*}$ for the different size of the original data sample and the bootstrap subsamples. We therefore adjust the quantile estimates by the factor $(m / n)^{2 /(p+q+1)}$ following Simar and Wilson (2008).

\section{Data Description}

The analysis is based on data from the Statistics of Waterworks (in Japanese: Suidou-Tokei) published by the Japan Water Works Association. This is the most comprehensive database on the water industry in Japan and contains detailed information on all LWS and BWS at license level. Water utilities' service areas are usually based on one or more licenses. Data is provided on the level of such licenses as well as at company level. Since the license level data provides more detailed information, we aggregate the detailed license level data to obtain aggregate company level data. All information is validated to avoid double counting of variables when aggregating license level data to company level data. Our analysis focuses on fully integrated LWS companies that carry out both water production and water distribution activities and do not purchase purified water from bulk water supply companies. This allows a consistent production frontier to be estimated for all firms in the sample, thereby allowing us to focus primarily on demonstrating our merger consistent decomposition. The observed water utility consolidations in response to mandated municipal consolidation took place in 2004 and 2005. We therefore assume a base period of 2003 as the last year before consolidation began, and evaluate realized productivity gains relative to the year 2009 data, e.g. the last available year of data at the time of analysis.

Table 2 illustrates the details of the underlying data. Between 2003 and 2009 the overall number of observed integrated LWS companies in the database declined from 996 to 661 . Over the same period, merger consolidation of the observed 479 predecessor firms left 156 observed merged companies. In contrast, the number of observed non-merging integrated LWS companies declined from 517 to 505, revealing that we have an unbalanced panel even for non-merging firms. However, after carrying out a thorough data cleaning process which removed empirically unreliable observations and outliers from our analysis, the total number of observations employed to estimate the 2003 DEA frontier was $n_{2003}=$ 762 , while $n_{2009}=561$ observations were employed for the 2009 frontier. Thus, 357 merger predecessor companies and 405 non-merging companies are included in the 2003 DEA analysis, while 432 nonmerging observations and 129 merged observations are included in the 2009 DEA frontiers.

\footnotetext{
${ }^{12}$ The application of the subsampling bootstrap approach can lead to infeasible solutions for efficiency scores of an observation in some subsamples. We assume an efficiency score of 1 in such cases since this does not influence the asymptotic properties of the subsampling bootstrap approach (Simar and Wilson, 2008).
} 
The final row of Table 2 details the available number of observations for which productivity analysis can reliably be carried out. Thus, we have 356 non-merging companies for which reliable data is observed in both 2003 and 2009. Looking at the merging companies, 63 additive companies can be constructed from the reliable 2003 data that are also observed as real merged companies in 2009. The year 2003 additive merger companies are obtained by simple aggregation of individual predecessor firms' inputs and outputs. Thus, the 63 reliable merger cases for productivity analysis resulted from 46 two firm mergers, 11 three firm mergers, 5 four firm mergers, and 1 five firm merger.

Table 2. Available Observations for Frontier Estimation and Productivity Analysis

\begin{tabular}{cccc}
\hline & All Companies & Non-Merging Companies & Merging Companies \\
\hline Underlying Raw Data & & & \\
2003 & 996 & 517 & 479 \\
2009 & 661 & 505 & 156 \\
\hline Clean Data Employed in Frontier Estimation & & \\
2003 & 762 & 405 & 357 \\
2009 & 561 & 432 & 129 \\
\hline Consistent Observations for Productivity Analysis & 356 & 63 \\
\hline
\end{tabular}

Table 3 describes and presents summary statistics of the considered input and output variables, corresponding to the clean data sample of 762 and 561 observations respectively used for estimation of the 2003 and 2009 frontiers, but further divided into merger and non-merger companies to better illustrate the sample characteristics.

Our specification assumes the physical capital stocks, the number of employees and the expenditures for energy and other inputs as input variables. This specification is in line with standard input specifications for production models and has been applied e.g. by De Witte and Marques (2010) in a similar manner. The capital stock variable measures the tangible fixed assets of the LWS consisting of land and buildings, depreciable assets, accumulated depreciation and other tangible fixed assets as contained in the water utilities' balance sheets. The book values are adjusted for inflation using the Perpetual Inventory Method (PIM) and are expressed in year 2003 Yen. In the Appendix we describe the methodology for adjusting capital stocks for inflation in more detail. Labor input is measured by the number of employees in the water utilities' profit and loss accounts. Expenditures for energy and other inputs consist of total annual power costs, chemical costs, other costs as well as repair and maintenance costs. Power costs are deflated using the corporate goods price index for electricity provided by the Bank of Japan, and other expenditures are deflated using an input price index for the water industry provided by Bank of Japan. All monetary values are expressed in year 2003 Yen. As output variables, 
we include the annual effective amount of water deliveries, i.e. water deliveries excluding water losses, and the number of connections in a service area. Similar output specifications have been applied in the empirical literature as illustrated by De Wittte and Marques (2010).

Table 3. Summary statistics of input and output variables

\begin{tabular}{|c|c|c|c|c|c|c|}
\hline & \multicolumn{6}{|c|}{ Pre-consolidation (2003) } \\
\hline & \multicolumn{4}{|c|}{ Full Sample } & Merge & Non-merge \\
\hline & Min & Mean & Max & sd. & Mean & Mean \\
\hline $\begin{array}{l}\mathrm{X}_{\mathrm{K}}-\text { Capital stock } \\
\text { [millions of year } 2003 \mathrm{JPY}]\end{array}$ & 45 & 6,433 & 329,340 & 20,784 & 5,929 & 6,878 \\
\hline $\begin{array}{l}\mathrm{x}_{\mathrm{L}}-\text { Employees } \\
\text { [number in FTE] }\end{array}$ & 1 & 22 & 2,088 & 104 & 20 & 24 \\
\hline $\begin{array}{l}\mathrm{X}_{\mathrm{O}}-\text { Other inputs } \\
\text { [millions of year } 2003 \mathrm{JPY}]\end{array}$ & 8 & 257 & 23,544 & 1,293 & 244 & 269 \\
\hline $\begin{array}{l}\mathrm{y}_{\mathrm{w}}-\text { Volume of water supply } \\
{[1000 \mathrm{~m} 3]}\end{array}$ & 137 & 5,576 & 442,201 & 22,897 & 5,172 & 5,932 \\
\hline $\begin{array}{l}\mathrm{y}_{\mathrm{C}}-\text { Connections } \\
\text { [number] }\end{array}$ & 150 & 17,053 & 896,009 & 59,336 & 16,105 & 17,890 \\
\hline \multirow[t]{3}{*}{ Number of observations } & & 762 & & & 357 & 405 \\
\hline & \multicolumn{6}{|c|}{ Post-consolidation (2009) } \\
\hline & \multicolumn{4}{|c|}{ Full Sample } & Merge & Non-merge \\
\hline $\begin{array}{l}\mathrm{X}_{\mathrm{K}}-\text { Capital stock } \\
\text { [millions of year } 2003 \mathrm{JPY}]\end{array}$ & 359 & 10,628 & 359,698 & 28,375 & 19,846 & 7,876 \\
\hline $\begin{array}{l}\mathrm{x}_{\mathrm{L}}-\text { Employees } \\
\text { [number in FTE] }\end{array}$ & 1 & 26 & 1,727 & 106 & 44 & 20 \\
\hline $\begin{array}{l}\mathrm{x}_{\mathrm{O}}-\text { Other inputs } \\
\text { [millions of year } 2003 \mathrm{JPY}]\end{array}$ & 7 & 358 & 24,263 & 1,491 & 646 & 272 \\
\hline $\begin{array}{l}\mathrm{y}_{\mathrm{w}}-\text { Volume of water supply } \\
{[1000 \mathrm{~m} 3]}\end{array}$ & 243 & 7,357 & 405,057 & 25,169 & 13,014 & 5,667 \\
\hline $\begin{array}{l}\mathrm{y}_{\mathrm{C}}-\text { Connections } \\
\text { [number] }\end{array}$ & 1,056 & 25,464 & 963,070 & 75,095 & 46,757 & 19,106 \\
\hline Number of observations & & 561 & & & 129 & 432 \\
\hline
\end{tabular}

\section{Results}

Given they are not our primary focus, we only briefly consider the estimated efficiency scores for the water supply systems in 2003 and 2009. Table 4 summarizes the VRS efficiency scores for all of the merger and non-merger companies for both 2003 and 2009. The efficiency scores are consistent with those normally obtained with such data, and show a broad equivalence between merger and non-merger observations. We note that while these efficiency scores range over a relatively wide interval, they are broadly consistent with previous analysis of efficiency in highly fragmented water systems. For example, Marques et al. (2014) finds very close estimates for Japanese water utilities in a sample covering 2004 to 2007. Likewise, Abrate, et al. (2017) find similar estimates for Italian water utilities. 
Table 4. Summary statistics of the VRS efficiency scores

\begin{tabular}{|c|c|c|}
\hline & Merging firms & Non Merging firms \\
\hline \multicolumn{3}{|l|}{2003} \\
\hline Min & 0.177 & 0.166 \\
\hline Average & 0.487 & 0.531 \\
\hline $\operatorname{Max}$ & 1.000 & 1.000 \\
\hline SD & 0.164 & 0.188 \\
\hline No. of observations & 357 & 405 \\
\hline \multicolumn{3}{|l|}{2009} \\
\hline Min & 0.307 & 0.200 \\
\hline Average & 0.523 & 0.561 \\
\hline Max & 1.000 & 1.000 \\
\hline $\mathrm{SD}$ & 0.178 & 0.196 \\
\hline No. of observations & 129 & 432 \\
\hline
\end{tabular}

Turning to the productivity results, Figure 2 provides an overview of the geometric averages of overall total factor productivity growth (MPI) and the corresponding decompositions for both merging and non-merging companies. ${ }^{13}$ In addition, Table 5 and 6 respectively summarize the bootstrap based statistical significances and the distribution of the estimates for merging and non-merging firms.

Figure 2. Productivity change and its components for merging and non-merging companies (geometric averages)

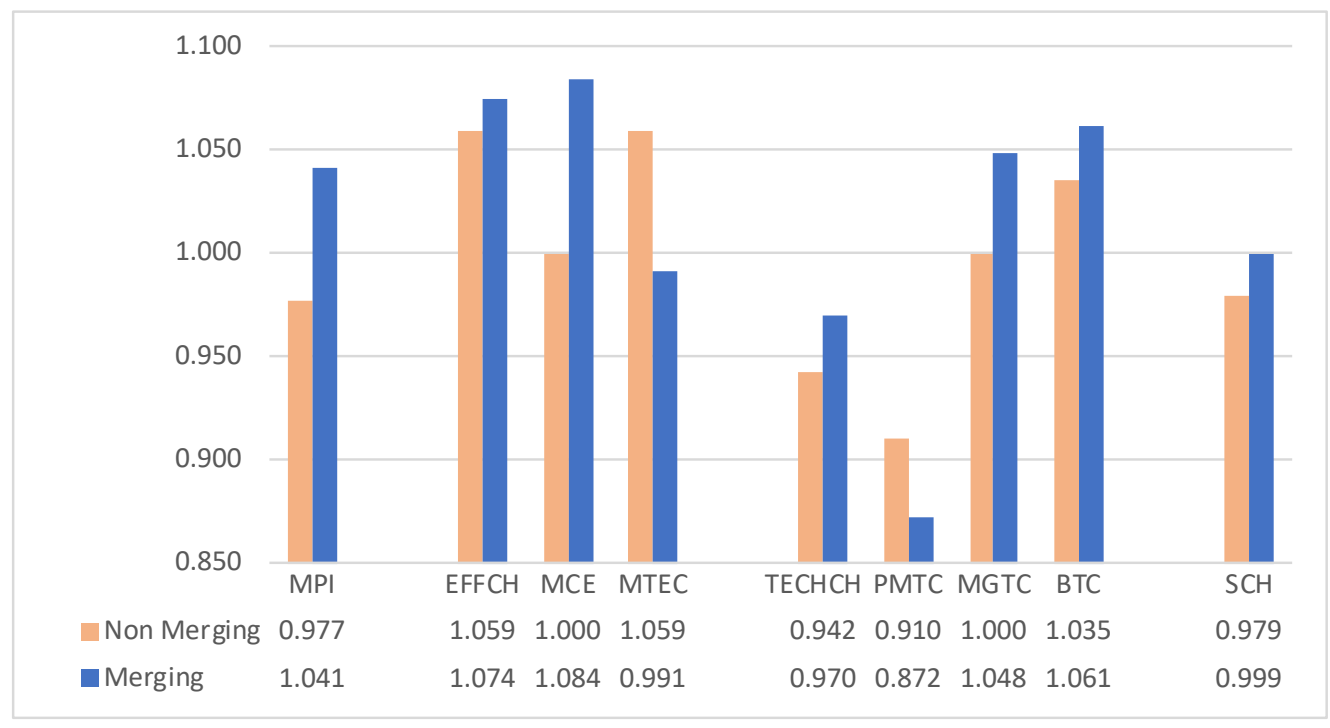

Focusing first on the overall productivity estimates, the first pair of bars in Figure 2 shows that, on average, the productivity of the 63 merging firms increased by $4.1 \%$ between 2003 and 2009, while the average MPI is found to be lower than one for the 356 non-merger companies (0.977), thus indicating a productivity decline of $2.3 \%$ over the same period for these firms. This trend of merging firms outperforming non-merging firms' productivity growth is further supported in the top panel of Table 5,

\footnotetext{
${ }^{13} \mathrm{We}$ focus on the geometric mean because it preserves the multiplicative decomposition of the Malmquist index.
} 
as $57.1 \%$ of the merging companies show productivity improvement, while only $41.3 \%$ do in the case of non-merging companies. Moreover, the second panel of Table 5 reveals that $55.3 \%$ of the nonmerging firms actually had statistically significant productivity decline, while only $22.2 \%$ of the merging firms did, thereby evidencing differences in productivity performance between the two groups. ${ }^{14}$ On the other hand, the bottom panel of Table 5 reveals that the percentage of cases with statistically significant productivity increases is only moderately higher in the non-merging group (33.4\%) than in the merging group (28.6\%). Thus, the geometric averages as well as the bootstrap based statistical significance tests suggest lower productivity performance for the non-merging companies.

We therefore further consider if the magnitude of productivity change can be demonstrated to be statistically different for the sample of merging firms in comparison to the non-merging group. To that end, Table 6 first summarizes the value of the percentiles of the distribution of MPI and each element of the productivity decomposition for both firm groups: It demonstrates that the merging firms show higher values in all percentiles of the distribution of the overall estimated MPI productivity change. ${ }^{15}$ Moreover, Table 6 reports Mood's median test of the null hypothesis that the medians of the merging and non-merging samples are identical, as well as the Mann Whitney and Kolmogorov-Smirnov tests to test the null hypothesis that the two samples have the same distribution. Results of the significance tests are reported at the bottom of Table 6 . The three tests reject the null hypothesis, indicating a significantly higher estimated MPI productivity growth for the sample of merged firms with respect to the sample of non-merged firms.

Let us now further consider the components of MPI. On average, Figure 2 reveals a positive 7.4 percent geometric average contribution to productivity growth for merging firms from EFFCH, which exceeds the 5.9 percent average estimate for non-merging firms. However, as discussed above, while EFFCH is the standard measure of technical efficiency change employed in most Malmquist decompositions, it is not merger consistent. Thus, our merger consistent decomposition suggest that, on average, this gain should be attributed to a strong merger consolidation effect (MCE) of $8.4 \%$ for merging companies. That is, on average we find a positive direct impact of mergers attributable to the improvement of production possibilities from consolidated firms relative to their stand-alone predecessors. Moreover, once this improvement in production possibilities from consolidation is accounted for, our merger corrected estimate of technical efficiency change (MTEC) suggests a weak negative average contribution of technical efficiency change of 0.991 , which compares unfavorably to the 1.059 average estimate for non-merging firms. On balance, these estimates imply that on average

\footnotetext{
${ }^{14}$ As discussed above, with the confidence intervals defined in (23) it is possible to determine whether individual productivity change is significant, i.e. if the index is greater than (or less than) unity at the $95 \%$ significance level. ${ }^{15}$ Recalling that our study provides estimates for a 6 year period, we wish to emphasise the relatively narrow range that 90 percent of our productivity decomposition estimates fall into as defined by the 5 th and 95 th percentiles in Table 6. Moreoever, we note that respectively only $6.9,0.2,7.6,2.1,0.0,1.2$, and 1.9 percent of the individual MPI,MCE,MTEC,PMTC,MGTC, BTC, and SCH estimates fall outside the range of 0.70-1.60, with no meaningful deviation in these shares between merging and non-merging firms.
} 
while consolidation did substantially improve the potential performance of merged firms, the merged companies did not catch up all of this potential productivity improvement, which might be a reflection of the presence of managerial difficulties following a merger, as discussed in the introduction.

Table 5. Summary of individual estimates and statistical significance based on bootstrap confidence intervals

\begin{tabular}{|c|c|c|c|c|c|c|c|}
\hline \multicolumn{8}{|c|}{ Individual estimates that are greater than 1 regardless of statistical significance } \\
\hline & MPI & MCE & MTEC & PMTC & MGTC & BTC & SCH \\
\hline \multicolumn{8}{|c|}{ Number of Estimates } \\
\hline Merging & 36 & 42 & 33 & 9 & 39 & 46 & 38 \\
\hline Non-Merging & 147 & 0 & 208 & 84 & 0 & 218 & 154 \\
\hline \multicolumn{8}{|c|}{ Percentage of All Estimates } \\
\hline Merging & 57.1 & 66.7 & 52.4 & 14.3 & 61.9 & 73 & 60.3 \\
\hline Non-Merging & 41.3 & 0 & 58.4 & 23.6 & 0 & 61.2 & 43.3 \\
\hline \multicolumn{8}{|c|}{ Individual Estimates that are statistically significantly less than 1} \\
\hline & MPI & MCE & MTEC & PMTC & MGTC & BTC & SCH \\
\hline \multicolumn{8}{|c|}{ Number of Estimates } \\
\hline Merging & 14 & 7 & 11 & 8 & 0 & 1 & 3 \\
\hline Non-Merging & 197 & 0 & 37 & 270 & 0 & 0 & 6 \\
\hline \multicolumn{8}{|c|}{ Percentage of All Estimates } \\
\hline Merging & 22.2 & 11.1 & 17.5 & 12.7 & 0 & 1.6 & 4.8 \\
\hline Non-Merging & 55.3 & 0 & 10.4 & 75.8 & 0 & 0 & 1.7 \\
\hline \multicolumn{8}{|c|}{ Individual estimates that are statistically significantly greater than 1} \\
\hline & MPI & MCE & MTEC & PMTC & MGTC & BTC & SCH \\
\hline \multicolumn{8}{|c|}{ Number of Estimates } \\
\hline Merging & 18 & 11 & 3 & 0 & 9 & 7 & 0 \\
\hline Non-Merging & 119 & 0 & 47 & 0 & 0 & 162 & 2 \\
\hline \multicolumn{8}{|c|}{ Percentage of All Estimates } \\
\hline Merging & 28.6 & 17.5 & 4.8 & 0 & 14.3 & 11.1 & 0 \\
\hline Non-Merging & 33.4 & 0 & 13.2 & 0 & 0 & 45.5 & 0.6 \\
\hline
\end{tabular}

Table 6. Summary of the Malmquist Productivity Index and its decomposition

\begin{tabular}{lccccccc}
\hline Merging Firms (63 obs.) & MPI & MCE & MTEC & PMTC & MGTC & BTC & SCH \\
\hline Minimum & 0.657 & 0.927 & 0.587 & 0.646 & 0.807 & 0.81 & 0.604 \\
5th Percentile & 0.780 & 0.951 & 0.678 & 0.704 & 0.896 & 0.87 & 0.915 \\
25th Percentile & 0.917 & 0.992 & 0.846 & 0.799 & 0.981 & 0.99 & 0.986 \\
Median & 1.021 & 1.040 & 1.006 & 0.863 & 1.027 & 1.05 & 1.010 \\
75th Percentile & 1.123 & 1.134 & 1.114 & 0.953 & 1.106 & 1.10 & 1.045 \\
95th Percentile & 1.507 & 1.452 & 1.368 & 1.108 & 1.336 & 1.34 & 1.090 \\
Maximum & 3.045 & 1.709 & 2.490 & 1.179 & 1.391 & 1.75 & 1.138 \\
\hline Non-Merging Firms (356 obs.) & MPI & MCE & MTEC & PMTC & MGTC & BTC & SCH \\
\hline Minimum & 0.488 & 1 & 0.537 & 0.627 & 1 & 0.70 & 0.335 \\
5th Percentile & 0.735 & 1 & 0.730 & 0.748 & 1 & 0.85 & 0.839 \\
25th Percentile & 0.867 & 1 & 0.942 & 0.833 & 1 & 0.96 & 0.965 \\
Median & 0.964 & 1 & 1.044 & 0.899 & 1 & 1.02 & 0.996 \\
75th Percentile & 1.079 & 1 & 1.212 & 0.990 & 1 & 1.08 & 1.011 \\
95th Percentile & 1.379 & 1 & 1.502 & 1.156 & 1 & 1.27 & 1.067 \\
Maximum & 2.939 & 1 & 2.419 & 1.396 & 1 & 3.48 & 2.927 \\
\hline Significance tests & MPI & MCE & MTEC & PMTC & MGTC & BTC & SCH \\
\hline Median Dif Test & 4.29 & 263.77 & 2.2 & 5.3 & 243 & 2.32 & 5.5 \\
Mann-Whitney & -2.33 & -7.16 & -2.26 & -2.22 & -4.85 & -1.77 & -3.16 \\
Kolmogorov-Smirnov & 1.43 & 4.88 & 1.21 & 1.3 & 4.53 & 1.23 & 2.04 \\
\hline Significance tests- statistical sig. & MPI & MCE & MTEC & PMTC & MGTC & BTC & SCH \\
\hline Median Dif Test & 0.04 & 0 & 0.14 & 0.02 & 0 & 0.13 & 0.02 \\
Mann-Whitney & 0.01 & 0 & 0.01 & 0.01 & 0 & 0.04 & 0 \\
Kolmogorov-Smirnov & 0.03 & 0 & 0.09 & 0.06 & 0 & 0.08 & 0 \\
\hline
\end{tabular}


Furthermore, a review of the statistics summarized in Table 5 and Table 6, suggests that non-merging firms have increased their efficiency significantly more than merged firms. This result suggests that despite positive merger consolidation effects, mergers have failed to improve the management of merging firms in fostering an efficient utilization of resources.

With regard to technical change, Figure 2 reveals that TECHCH, the overall estimate consistent with Ray and Desli's (1997) Malmquist decomposition, was on average negative for both merging firms (0.970) and non-merging firms (0.942). Thus, the 3.0 percent average deterioration for merging firms must be seen as superior to the average deterioration registered by non-merging firms (5.8\%). Such general technical regress is not surprising at all, being consistent with the overall decrease of the output levels observed in Japanese water supply, as a result of the continued nationwide decline in per capita water consumption, as well as the impact of slow or even negative population growth. Our results are therefore capturing the impact of one of the key issues that Japanese policy makers are dealing with, as they strive to maintain and fund an infrastructure system given significant predicted future declines in population (Urakami, 2019).

Moreover, our merger consistent decomposition of technical change reinforces this impression that consolidation allowed firms to experience superior technical change. Firstly, the average index of technical change that would have occurred in the absence of mergers (pre-merger technical change, PMTC) is highly negative (0.872) for merging firms, and consistently below and statistically different than that for non-merging firms (0.910) as shown in Table 6. This suggests that technical change would have been lower in the absence of mergers.

Secondly, Figure 2 illustrates that merger gap technical change (MGTC), which measures how technical change impacted the increase in production possibilities from merger consolidation, averaged 4.1 percent for merged firms, thereby reinforcing the 8.4 percent average merger consolidation effect. Thus, technical change appears to have changed production possibilities in a manner which increased the potential benefits of merger consolidation between 2003 and 2009. Moreover, Figure 2 reveals that the bias of technical change (BTC) is found to be positive, with respective average values of 1.035 and 1.061 for non-merged and merged firms. This suggests that post-merger change in input and output quantities from additive 2003 quantities to observed 2009 quantities fostered stronger technical change for merged firms than non-merger firms, although the tests provided in Tables 5 and 6 suggest that this effect is not statistically significant. Thus, it is important to emphasize that our merger consistent decomposition of technical change effectively demonstrate that in addition to experiencing the benefits captured by the pure merger consolidation effect, the process of technical change appears to have increased the potential productivity of merged firms more than non-merged firms.

We finally find, on average, no contribution of post-merger scale effects to the productivity growth of merged firms as the average value of SCH is very close to unity (0.999). For non-merging firms, scale change is found to have a negative average impact on their productivity (0.979), with the group of merging firms achieving statistically significant higher values than the group of non-merging 
firms in the median and in all the percentiles displayed in Table 6. Despite this statistically significant difference between the two groups Table 5 suggests that over 95 percent of the estimates for both merging and non-merging firms are not individually statistically different than 1 . On consideration, these results are consistent with a context where no, or even declining, population growth results in small "natural" changes in the scale of water outputs, while in contrast consolidation of fragmented firms allows for substantial potential improvements in potential production possibilities. Stated differently, when taken in tandem with our above conclusions with regard to the merger consolidation effect (MCE) and merger gap technical change (MGTC), our results tend to support the benefit of merger based consolidation as an appropriate policy response that will improve the productivity of the fragmented Japanese water sector. However, our estimates for MTEC suggest the further need for improving managerial capacity to transform the potential benefits of consolidation into realized benefits.

In order to further explore these policy considerations, we analyze the differences in productivity growth across two important merger characteristics: merger size and internal diversity of the merger as illustrated in Table 7. Focusing first on firm size, the top panel of Table 7 shows the relationship between the geometric average of productivity growth and its components for merging firms in different size groups, with the size groups defined based on population served in 2009.

Table 7. Group Geometric Averages of the Malmquist Productivity Index and its Components

\begin{tabular}{|c|c|c|c|c|c|c|c|c|}
\hline \multicolumn{9}{|c|}{ Merging Firms by 2009 Population (000) Size Groups } \\
\hline & obs. & MPI & MCE & MTEC & PMTC & MGTC & BTC & SCH \\
\hline$<20$ & 10 & 1.048 & 1.338 & 0.847 & 0.825 & 1.098 & 1.040 & 0.982 \\
\hline $20-40$ & 21 & 1.091 & 1.106 & 0.967 & 0.884 & 1.111 & 1.037 & 1.002 \\
\hline $40-60$ & 10 & 1.022 & 1.018 & 1.002 & 0.938 & 0.991 & 1.036 & 1.040 \\
\hline $60-120$ & 9 & 1.026 & 1.022 & 1.041 & 0.917 & 0.997 & 1.071 & 0.984 \\
\hline$>120$ & 13 & 0.983 & 0.974 & 1.117 & 0.812 & 0.996 & 1.132 & 0.987 \\
\hline All Firms & 63 & 1.041 & 1.084 & 0.991 & 0.872 & 1.048 & 1.061 & 0.999 \\
\hline \multicolumn{9}{|c|}{ Merging Firms By Diversity Index Groups } \\
\hline & obs. & MPI & MCE & MTEC & PMTC & MGTC & BTC & SCH \\
\hline$>0.50$ & 9 & 0.951 & 1.111 & 0.891 & 0.789 & 1.206 & 0.975 & 1.034 \\
\hline $0.40-0.50$ & 23 & 1.161 & 1.181 & 0.996 & 0.915 & 1.037 & 1.076 & 0.967 \\
\hline $0.30-0.40$ & 16 & 1.014 & 1.032 & 0.999 & 0.897 & 1.020 & 1.040 & 1.034 \\
\hline $0.10-0.30$ & 9 & 0.998 & 1.002 & 1.037 & 0.869 & 1.000 & 1.090 & 1.014 \\
\hline $0.00-0.10$ & 6 & 0.892 & 0.962 & 1.043 & 0.784 & 1.022 & 1.158 & 0.959 \\
\hline All Firms & 63 & 1.041 & 1.084 & 0.991 & 0.872 & 1.048 & 1.061 & 0.999 \\
\hline
\end{tabular}

Thus, the results suggest that both the highest group average productivity growth (MPI), and highest merger consolidation effects (MCE) and MGTC estimates were realized for mergers resulting in firms serving up to 40,000 thousand customers. In contrast, mergers resulting in firms with population in excess of 120,000 customers were the only group of merged firms with overall negative productivity growth (0.982) and negative MCE (0.974). Thus, our results suggest that the merger consolidation benefits are greatest for the smallest firms and are exhausted at a population of approximately 120,000. Interestingly, the size group estimates for MTEC shows the opposite trend: merged firms serving up to 20,000 and 40,000 people respectively have negative MTEC estimates of 0.847 and 0.967 , while those 
serving more than 120,000 people had a group average MTEC estimate of 1.117 . We believe these results suggest that while mergers of smaller more equally sized utilities had greater technological potential consolidation benefits, limits to managerial capacity in such small entities, as well as potential difficulties in integrating the facilities, culture, and operations of similar sized entities, restrict the potential for managers to realize potential consolidation benefits. In contrast, while large existing utilities that absorb relatively small utilities may not benefit from substantial technological consolidation benefits, the greater managerial capacity of the larger entity, and its stronger potential to impose its culture on the smaller entity, may substantially improve the potential for achieving efficiency improvements via mergers.

Turning next to the relationship between the diversity of mergers and productivity, discussed in the introduction section, any merger requires the integration of predecessors that may have different, sometimes divergent, organization systems and strategic goals. Such differences may undermine the scope of the subsequent business and managerial transformations. The integration process largely depends on the relative power and control that the predecessors are able to exert. Thus, it is likely that decision making is more difficult and the integration process more troubled to implement, when a merger involves many predecessors with similar size (importance and influencing power), than in the case of a merge between a large company and a much smaller one. In the latter case, it is like a takeover or merger by absorption, resulting in a comparatively more homogeneous merged entity, which in principle should entail fewer changes with respect to the governance and management of the largest predecessor.

We therefore define a measure of the degree of internal diversity for each observed merging firm as

$$
D=1-\sum_{p=1}^{P} s_{p}^{2}
$$

where $s_{p}$ is the weight or size share of predecessor $p$ in the merged firm $f$ which is integrated by $P$ predecessors. The size is measured by the population served $\left(P O P_{p}\right)$, i.e. $s_{p}=\frac{P O P_{p}}{\sum_{p=1}^{P} P O P_{p}}$. It is easy to note that the diversity index $D$ in (22) is structured as one minus a Herfindahl-Hirschman concentration index that is calculated by the sum of the squares of the population share of all predecessors that integrate the firm $f$. Thus, the value of $D$ is determined by both the number of predecessors and their relative size (i.e. how evenly the constituents are present in the merged company). The higher the value of $D$, the higher the diversity of the merged company. ${ }^{16}$ One may expect that more (less) diverse mergers would attain lower (higher) improvement in technical efficiency due to the problems related to governance referred to above.

\footnotetext{
${ }^{16}$ Thus, a merger involving three predecessors of identical size results in $D=0.67$, while a merger between two firms with the size of one being four times bigger than the size of the other gives a diversity value of $D=0.32$. It should be obvious that for the non-merging firms the value of $D$ is always 0 (no diversity).
} 
The second panel of Table 7 supports this hypothesis, as the group average for MTEC systematically increases from 0.891 for merged firms with a diversity index greater than 0.50 to 1.043 for merged firms with a diversity index less than 0.10 . However, this panel also demonstrates what appears to be a tension between the potential benefits of a merger and the capacity to realize those benefits, as the most diverse merger group has a MCE of 1.111 while the least diverse group has a much lower MCE of 0.962. This apparent tradeoff appears to be best balanced in the group of 23 firms with a diversity index between 0.40 and 0.50 who achieve the highest group average MPI (1.161) as a result of a strong average MCE (1.181) and relatively strong capacity to maintain, if not achieve, increased efficiency (0.996). ${ }^{17}$

\section{Summary and Conclusions}

This paper has developed a decomposition of the Malmquist productivity change index, which unlike previous decompositions is consistent in the case of mergers. Specifically, it compares the productivity of one company resulting from the merger of a number of firms, with that of its predecessors when considering their aggregated production in the pre-merged state. The productivity change index is subsequently decomposed into six explanatory elements: merger consolidation effect, technical efficiency change, pre-merger technical change, merger gap technical change, bias of technical change, and the scale change effect. The proposed approach focuses on the assessment of the productivity change of realized mergers. It therefore extends previous related approaches (e.g. Bogetoft and Wang 2005, Ray 2004), which focus on an ex-ante analysis of the potential benefits of mergers and break-up of firms, and are only appropriate for application in a static context using a single (pre-merger) cross-sectional analysis.

We have illustrated the empirical applicability of our merger consistent Malmquist index decomposition by analyzing the productivity impact of water supply system consolidation that followed the mandatory consolidation of some municipalities by the Japanese Government during the Great Heisei Era consolidation. Nevertheless, our methodological approach provides a useful widely applicable tool to identify the contribution of past mergers to productivity growth in any industry.

We find that the average productivity growth of merging water supply systems is significantly higher than that of non-merger companies. Moreover, our merger consistent decomposition suggests that, on average, mergers contributed positively to productivity change. This occurred via both the merger consolidation effect and the merger gap technical change effect. Thus, our results strongly suggest that merger consolidation has not only contributed positively to average water supply

\footnotetext{
${ }^{17}$ Given the strong negative correlation of -0.67 between the Diversity index and population served for the merged firm in 2009, it is not surprising that a similar balancing of potential benefits resulting from the merger consolidation effect and apparent reasonable managerial capacity to realize those potential benefits (MTEC) supported the highest group average MPI (1.091) for merged firms serving a population between 20 and 40 thousand people.
} 
productivity growth, but that the productivity benefits associated with consolidation increased over time. Within the context of the Japanese water supply sector, application of our merger consistent Malmquist productivity decomposition suggests that mergers have a positive consolidation effect. However, consideration of our merger consistent efficiency change estimates do suggest a need for improved managerial capacity to transform the potential benefits of consolidation into realized benefits, and that this is particularly the case for smaller merged firms and those mergers that brings together more diversified predecessor firms.

Nevertheless, on balance our results suggest that the mandatory consolidation of municipal water supply systems did contribute significantly to water supply productivity growth. However, our review of the current structure of Japanese water sector also demonstrates the continued fragmented nature of the sector. Furthermore, while the Japanese government has attempted to promote further consolidation via voluntary wide area consolidation policies, encouraging mergers of water operations into companies that will be jointly owned by municipalities, and contracting out of water supply operations in public private partnerships, these policies have had very limited success. We therefore suggest that further research should provide evidence with regard to the potential benefits that could be achieved via further horizontal and vertical integration of the sector, and also identify methodologies that will allow policy makers to measure which consolidations are likely to be most beneficial. Future research might also explore how varying the length of time over which productivity change is evaluated influences the assessment of the merger impact. Similarly, future research might expand our analysis on what factors influence the ability of managers to carry out the reconfiguration of the merged firm required to achieve the full potential benefits of the merger.

\section{Acknowledgments}

Pablo Arocena acknowledges financial support from the Spanish Ministry of Economy and Competitiveness (project ECO2017-86054-C3-2-R).Takuya Urakami acknowledges financial support from JSPS Grant-in-Aid for Scientific Research(C) Grant Number 17K03738. Michael Zschille acknowledges support from DIW Berlin - German Institute for Economic Research, Germany where research on the paper was also conducted. Finally, we are very grateful to the Editor and three anonymous reviewers for their careful reading of our manuscript and their many insightful comments and suggestions.

\section{References}

Abrate, G., Bruno, C., Erbetta, F., Fraquelli, G. \& Giolitti, A. (2017). Efficiency in the Consolidation of the Italian Water Sector. Water Resource Management, 31, 2447-2463.

Bernad, C., Fuentelsaz, L., \& Gómez, J. (2010). The effect of mergers and acquisitions on productivity: An empirical application to Spanish banking. Omega, 38(5), 283-293. 
Bjurek, H., Forsund, F.R. \& Hjalmarsson, L. (1998). Malmquist productivity indexes: An empirical comparison. In Färe, R. Grosskopf, S. and Russell, R. (eds) Index Numbers: Essays in Honour of Sten Malmquist (pp.217-239). Kluwer Academic Publishers.

Bogetoft, P. \& Wang, D. (2005). Estimating the potential gains from mergers. Journal of Productivity Analysis, 23(2), 145-171.

Capron, L., Dussauge, P. \& Mitchell, W. (1998). Resource deployment following horizontal acquisitions in Europe and North America, 1988-1992. Strategic Management Journal, 19, 631-661.

Caves, D.W., Christensen, L.R. and Diewert, W.E. (1982). The Economic Theory of Index Numbers and the Measurement of Input, Output, and Productivity. Econometrica 50, 1393-1414.

Caves, R. (1989). Mergers, takeovers, and economic efficiency: foresight vs. hindsight. International Journal of Industrial Organization, 7, 151-174.

Cowing, T.G., Stevenson, R.E., \& Small, J. (1981). Comparative measures of total factor productivity in the regulated sector: the electric utility industry. In T.G. Cowing \& R.E. Stevenson (Eds.), Productivity Measurement in Regulated Industries. (pp. 161-177). New York: Academic Press.

De Witte K., \& Marques, R.C. (2010). Designing performance incentives, an international benchmark study in the water sector. Central European Journal of Operations Research, 18(2), 189-220.

De Witte, K. \& Dijkgraaf, E. (2010). Mean and bold? On separating merger economies from structural efficiency gains in the drinking water sector. Journal of the Operational Research Society, 61(2), 222-234.

Färe, R., Grifell-Tatjé E., Grosskopf S., \& Lovell, C. A. K. (1997). Biased Technical Change and the Malmquist Productivity Index. Scandinavian Journal of Economics, 99(1), 119-127.

Färe, R., Grosskopf, S., Norris, M. \& Zhang, Z. (1994). "Productivity growth, technical progress, and efficiency change in industrialized countries". American Economic Review, 84, 66-83.

Farrell, M.J. (1957). The measurement of productive efficiency. Journal of the Royal Statistical Society Series A, 120, 253-281.

Ferrier, G. D., \& Valdmanis, V. G. (2004). Do mergers improve hospital productivity? Journal of the Operational Research Society, 55(10), 1071-1080.

Gilsdorf, K. (1994). Vertical integration efficiencies and electric utilities: a cost complementarity perspective. Quarterly Review of Economics and Finance, 34 (3), 261- 282.

Grifell-Tatjé, E., \& Lovell, C. A. K. (1996). Deregulation and productivity decline: The case of Spanish savings banks. European Economic Review, 40, 1281-1303.

Grifell-Tatjé, E., \& Lovell, C. A. K. (1997a). The sources of productivity change in Spanish banking. European Journal of Operational Research, 98, 364-380.

Grifell-Tatjé, E., \& Lovell, C. A. K. (1997b). A DEA-based analysis of productivity change and intertemporal managerial performance. Annals of Operations Research, 73, 177-189.

Grifell-Tatjé, E., \& Lovell, C. A. K. (1999). A Generalized Malmquist Productivity Index. Top 7(1), $81-101$. 
Haneda, S., Hashimoto, A., \& Tsuneyoshi, T. (2012). Evaluating administrative efficiency change in the post-merger period: a study on Ibaraki prefecture (1979-2004). International Regional Science Review, 35(2), 237-262.

JWWA (2004). A guidance of water utility merger due to the local governments' consolidation, (written in Japanese Shichoson Gappei ni Tomonau Suidojigyo Togo no Tebiki). Tokyo: Japan Water Works Association.

Kneip A., Simar, L. and P. Wilson (2018). Inference in Dynamic, Nonparametric Models of Production: Central Limit Theorems for Malmquist Indices. Discussion Paper 2018/10. Institut de Statistique, Biostatistique et Sciences Actuarielles (ISBA). Université Catholique de Louvain.

Lovell, C. A. K. (2003). The decomposition of Malmquist productivity indexes. Journal of Productivity Analysis, 20(3), 437-458.

Marques, R. C., Berg, S., \& Yane, S. (2013). Nonparametric benchmarking of Japanese water utilities: institutional and environmental factors affecting efficiency. Journal of Water Resources Planning and Management, 140(5), 562-571.

MHLW (2017). Policy and administration of water supply in Japan. Ministry of Health, Labour and Welfare. Available at: http://www.mhlw.go.jp/english/policy/health/water_supply/dl/policy_admin.pdf as of 26/8/2017.

Mizutani, F. (2012). Regulatory Reform of Public Utilities: The Japanese Experience. Cheltenham: Edward Elgar Publishing.

Nemoto J., \& Goto, M. (2004). Technological externalities and economies of vertical integration in the electric utility industry. International Journal of Industrial Organization, 22, 67-81.

NIPSSR (2017). Population Projections for Japan: 2016 to 2065. Appendix: Auxiliary Projections 2066 to 2115. Tokyo: National Institute of Population and Social Security Research. Available at: www.ipss.go.jp/pp-zenkoku/e/zenkoku_e2017/pp29_summary.pdf

Odeck, J. (2008). The effect of mergers on efficiency and productivity of public transport services. Transportation Research Part A, 42(4), 696-708.

Pastor, J. \& Lovell, C.A.K. (2005). A global Malmquist productivity index. Economics Letters 88, 266271.

Pastor, J.T., Asmild, M. \& Lovell, C.A.K. (2011). The biennial Malmquist productivity change index. Socio-Economic Planning Sciences, 45, 10-15.

Ray, S. \& Desli, E. (1997). Productivity growth, technical progress, and efficiency change in industrialized countries: comment. American Economic Review, 87, 1033-39.

Ray, S. (2004) Data Envelopment Analysis: Theory and Techniques for Economics and Operations Research. Cambridge University Press.

Röller, L-H., Stennek, J., \& Verbohen, F. (2001). Efficiency gains from mergers. In The efficiency defence and the European system of merger control, European Economy Reports and Studies, No 5. European Commission. Directorate General for Economic and Financial Affairs. 
Saal, D.S., Arocena, P., Maziotis, A., \& Triebs, T. (2011). Scale and scope economies and the efficient vertical and horizontal configuration of the water industry: a survey of the literature. Review of Network Economics, 12(1), 93-129.

Saal, D.S., Parker, D. and Weyman-Jones, T. (2007) Determining the contribution of technical change, efficiency change and scale change to productivity growth in the privatized English and Welsh water and sewerage industry: 1985-2000. Journal of Productivity Analysis, 28(1/2), pp. 127-139

Sherman, H.D., \& Rupert, T., (2006). Do bank mergers have hidden or foregone value? Realized and unrealized operating synergies in one bank merger. European Journal of Operational Research, $168,253-268$.

Simar, L., \& Wilson, P.W. (1998). Sensitivity analysis of efficiency scores: How to bootstrap in nonparametric frontier models. Management Science, 44, 49-61

Simar, L., \& Wilson, P.W. (1999). Estimating and bootstrapping Malmquist indices. European Journal of Operational Research, 115(3), 459-471.

Simar, L., \& Wilson, P.W. (2008). Statistical inference in nonparametric frontier models: recent developments and perspectives. In H.O. Fried, C.A.K. Lovell \& S.S. Schmid (Eds.), The measurement of productive efficiency and productivity growth (pp. 421-521).

Simar, L., \& Wilson, P.W. (2011). Inference by the $m$ out of $n$ bootstrap in nonparametric frontier Models. Journal of Productivity Analysis, 36, 33-53.

Stone \& Webster (2004). Investigation into evidence for economies of scale in the water and sewerage industry in England and Wales. Stone \& Webster Consultants, London.

Teerikangas, S., Very, P. (2006). The culture-performance relationship in M\&A: from Yes/No to how. British Journal of Management, 17, 31-48.

Tortosa-Ausina, E., Grifell-Tatjé, E., Armero, C., \& Conesa, D. (2008). Sensitivity analysis of efficiency and Malmquist productivity indices: An application to Spanish savings banks. European Journal of Operational Research, 184, 1062-1084.

Urakami, T. \& Parker, D. (2011). The effects of consolidation amongst Japanese water utilities: A hedonic cost function analysis. Urban Studies, 48(13), 2805-2825.

Urakami, T. (2008). Questionnaire survey report on the water utility merger after Great Heisei Era Consolidation (Original title in Japanese: Shichoson gappeigo no suidojigyo ni okeru jigyotogo ni kansuru anketochosa hokokusyo) Working Paper No. KEIEI 2008-0001. Faculty of Business Administration, Kinki University, Japan.

Urakami, T. (2019). "Recent Policy Changes in the Japanese Water Supply Industries," in Porcher, S. and S. Saussier (eds) Facing the Challenges of Water Governance, Ch.13: 347-366, Palgrave Macmillan, Cham, Switzerland.

Zofío, J. L. (2007). Malmquist productivity index decompositions: A unifying framework. Applied Economics, 39 (18), 2371-2387. 
Zschille, M. (2015). Consolidating the water industry: An analysis of the potential gains from horizontal integration in a conditional efficiency framework. Journal of Productivity Analysis, 44, 97-114. 


\section{APPENDIX. Estimation of inflation-adjusted capital stocks}

We apply the Perpetual Inventory Method (PIM) for the estimation of inflation-adjusted capital stocks. In its basic formulation, PIM can be expressed as:

$$
K_{t+1}=(1-\delta) \cdot K_{t}+I_{t} / P I_{t}
$$

The next-period capital stock $K_{t+l}$ thus is based on the depreciated current-period capital stock $(1-\delta) \cdot K_{t}$, where $\delta$ denotes the depreciation rate, and the deflated current-period capital investments $I_{t} / P I_{t}$, where $I_{t}$ denotes the investments in period $t$ and $P I$ a price index. We use firm-specific depreciation rates defined as the mean depreciation rate observed in the data for each company over time. We assume the average depreciation rates to lie within the interval [0.01;0.07]. Values lying outside this interval are replaced by the corresponding boundary values. As price index we use the corporate price index for capital goods (domestic) provided by Bank of Japan, the base year is 2003. Investments are defined as the sum of new construction and extension costs and construction and improvement costs.

Using PIM, however, it is necessary to define a base-period capital stock. Since the book values of capital stocks observed in the first year of the data are not adjusted for inflation, we use a triangularized weighted average of the capital goods price index to deflate the book values in each company's first year of observation. The idea of the triangularized weighted average of a price index has been developed by Cowing et al. (1981) and was applied e.g. by Gilsdorf (1994) or Nemoto and Goto (2004). For each company, the adjusted first-period capital stock $K_{0}^{a d j}$ is calculated as:

$$
K_{0}^{a d j}=\frac{K_{0}}{\sum_{j=1}^{T}\left(\frac{j}{\sum_{j=1}^{T} j} \cdot P I_{j}\right)}
$$

where $K_{0}$ represents the book value of the capital stock in the first year when a company is observed in the data and $P I$ denotes a price index. The book value of the capital stock in the first year of observation is thus divided by a weighted average of the price index over a water utilities' lifetime from the year of establishment of a water utility until the first year of observation in the data. The index represents the number of years from the year of establishment of a water utility until the first year of the water utility being observed in the data. Since the price index is only available from 1969 on, we assume 1969 to be the starting year for water utilities that were established earlier on. The price index is weighted less for earlier years while weights increase over a water utilities' lifetime. We choose the year 2003 as the base period.

For merger companies, we estimate the capital stock in the first year after a merger and then use PIM to roll the capital stock of the merged water utility forward until 2009, the year where we analyze the merged companies. For this purpose, we aggregate the adjusted capital stocks of the pre-merger companies based on the PIM estimates and assume this aggregate to be the base period capital stock of the merged water utility. We then again use PIM as described above to roll capital stocks forward until 2009. We again assume the company-specific average of the depreciation rates observed in the data as depreciation rates for the merged companies. 